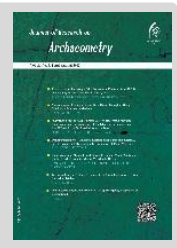

\title{
Structural Study of the Pastiglia and Gilding Decoration at the Vank Cathedral and Bethlehem Church in Isfahan
}

\author{
Tina Tinati ${ }^{1}$, Yaser Hamzavi ${ }^{*}$, Parviz Holakooei ${ }^{3}$, Maria Perla Colombini ${ }^{4}$ \\ ${ }^{1}$ Master of Archaeometry, Department of Applied Arts, Tabriz Islamic Art University, Tabriz, IRAN \\ ${ }^{2}$ Assistant Professor, Department of Applied Arts, Tabriz Islamic Art University, Tabriz, IRAN \\ ${ }^{3}$ Assistant Professor, Department of Art Conservation and Archaeometry, Art University of Isfahan, \\ Isfahan, IRAN \\ ${ }^{4}$ Professor, Department of Chemistry and Industrial Chemistry, University of Pisa, Pisa, ITALY
}

\begin{abstract}
The pastiglia technique has been widely used as the preparation layer for gilding decoration in Iran during the Safavid period. Generally, the purpose of pastiglia is to create a prominent surface for the gilding array. The main research issue is the lack of technical and structural knowledge of the layered arrays of the two churches under study. Lack of sufficient research and resources on the technical and structural knowledge of Pastiglia and gilding decorations in the Armenian churches of Julfa, and also the existence of technical ambiguities and lack of clarity on the origin of art of Isfahan Armenians, such as architectural decorations and especially Pastiglia art, are the necessities of doing this research. The present study provides a technological overview towards the pastiglia employed in the gilding decoration at the Bethlehem Church and Vank Cathedral, as two important Armenian monuments from the Safavid era at New Julfa in Isfahan, using pyrolysis-gas chromatography-mass spectrometry (Py-GC-MS), gas chromatography-mass spectrometry (GC/MS), X-ray diffractometry (XRD) and scanning electron microscope coupled with energy dispersive X-ray spectrometry (SEM-EDX). GC/MS and Py-GC-MS used for the characterization of organic materials of samples and XRD and SEM-EDX used for the characterization of inorganic materials of samples. The analytical data show that animal glue was used as a binding medium of pastiglia while linseed oil was probably employed as the mordant agent in the gilding decorations; furthermore, linseed oil was used as a varnish layer on the gilding decorations of Vank cathedral. Also, the inorganic part of the pastiglia substrate showed to have been composed of gypsum and an iron-rich clay. These results are discussed in the larger context of the pastiglia technique in other contemporary historical monuments in Isfahan. It can be said that this present research is looking for structural and technical differences and affinities of these decorations in Isfahan Armenian and Islamic buildings at Safavid era.
\end{abstract}

Keywords: Armenian Churches, Wall Decorations, Animal Glue, Linseed oil, Armenian Bole

\section{Introduction}

The great Safavid dynasty is the most vivid historical period of Iran. The pastiglia technique has been widely used as the preparation layer for gilding decoration in Iran during the Safavid period. Generally, the purpose of pastiglia is to create a prominent surface for the gilding array. This artistic technique is usually called

\footnotetext{
* :Corresponding author :y.hamzavi@tabriziau.ac.ir
}

Copyright (C) 2020, the Authors / This open-access article is published under the terms of the Creative Commons Attribution-NonCommercial 4.0 International License which permits Share (copy and redistribute the material in any - medium or format) and Adapt (remix, transform, and build upon the material) under the Attribution NonCommercial terms. 
"Pastiglia", which is an Italian word, but due to the various ways of performing, different names have been used in different cultures [1-6]. In various historical periods, several gilding techniques have been used in illumination and easel and mural paintings. Metal leaves such as gold, silver and tin have been widely used by artists in artworks to decorate, making precious and optical dynamism of the work. Bethlehem Church [fig.1] and Vank Cathedral (Surp Amenaprgich) [fig.2], the two holy places of the Safavid era, are the most famous Armenian churches in New Julfa of Isfahan with pastiglia and gilding decorations.

\section{Materials and Methods}

Py-GC-MS: Analyses were performed by using a multi-shot pyrolyser EGA/PY-3030D (Frontier Lab, Japan) coupled with a $6890 \mathrm{~N}$ gas chromatography system with a split/splitless injection port and combined with a 5973 mass selective single quadrupole mass spectrometer (Agilent Technologies, U.S.A.).

GC-MS: GC/MS instrumentation consisted of a Trace GC 2000 chromatographic system equipped with a PTV injection port and coupled to an ITQ 900 ion trap (Thermo Fisher, U.S.A.).

Peak assignment was based on a comparison with library mass spectra (NIST 1.7 main EI MS library, WILEY 275 MS library).

SEM/EDX: A MIRA3 model electron microscope (TESCAN, Czech Republic), with 15kV and 100pA, used for performing the analysis.

XRD: For performing the analysis, a D8 Advance model XRD instrument (Bruker), equipped with $\mathrm{Cu}-\mathrm{K} \alpha \mathrm{x}$ ray and with $1.5045 \AA$ wavelength, was used.

Identification of crystal phases was based on a comparison with International center for XRD data files (ICDD PDF); X'Pert HighScore Plus software was used for this.

\section{Results}

According to the hypothesis of the research, there could be the two types of organic materials in the samples (Gluing agent and Binder media). So, in order to gain the fingerprint of organic materials, Py-GC-MS was performed (Samples 2009.V.2 and 2010.B.1.). Then, according to the results, GC/MS analysis used for the identification of the organic materials $[21,23]$. The procedure of GC/MS that used in this research, is a multistep chemical pretreatments approach with primary extraction of organic compounds with ammonia solution, which was performed according to the procedure reported in the literature ref 14.

After confirming the presence of organic materials in the sample structure and identifying the type of these compounds, SEM pictograms were taken to investigate the morphological growth of the mineral crystals of the sample structure. EDX and XRD analyze were used to identify the constituents of minerals as the complementary analyzes.

Py-GC-MS: Palmitic acid and stearic acid peaks imply the lipid materials in samples structure (Figs. 3 and 4). Short chain fatty acids and homologues could be the results of the decomposition process of palmitic acid and stearic acid and or the same acidic compounds [30]. The pyrolysis product of proline and hydroxy proline is the pyrrole which its peak there is in the fig3. Due to the presence of the pyrrole (Fig. 3), proteinaceous material of the sample could be an animal glue [15]. Pyrolysis chromatograms shows that at least two kinds of organic materials was used in the pastiglia and gilding samples: Lipids and Proteins.

GC/MS: According to the (1) Py-GC-MS results which gave us a general idea about the organic materials of samples and (2) similarity of the Py-GC-MS results of the samples, GC/MS analysis used for the characterization of the organic materials in the sample 2010.B.1. The chromatographic separation of 2010.B.1 sample was performed at two different parts. First part of analysis was applied on the only pastiglia part of the sample (Code: 2010.B.1-pink). Second part of analysis was applied on the whole part of the sample (Code: 2010.B.1).

The extracted amino acids from 2010.B.1 and 2010.B.1-pink are the same (Chroma a, b; fig5).. There is lower amount of proteinaceous materials in 2010.B.1-pink respect to 2010.B.1. The Fig.6 shows the chromatograms of the lipid and resin materials of the sample 2010.B.1. Both of the two samples have proteinceous and lipid materials.

SEM: SEM Pictures confirms the presence of gluing media between the gold leaf and the pastiglia layers (Peak a, Fig.7, 8). Monoclinic crystals of gypsum are noticeable in Fig. 8 and 9. According to these pictures, there are some differences about the morphological growth of the pastiglia and the gypsum ground crystals.

3.4. EDX: With due attention to the EDX results of the pastiglia samples of the Vank cathedral and the 
Bethlehem church, maximum weight percentages of the identified elements belongs to the Calcium and Sulfur (Table 4); also, the most weight percentages of the identified elements of the plaster ground, in both churches samples, are belong to the calcium and sulfur too, which is foreseeable (Table 5).

XRD: The major phases of the inorganic materials of the samples (2010.V.1, 2009.V.2, 2010.B.1) are gypsum and quartz. In addition, in the sample 2010.B.1, hematite and in the sample 2009.V.2, anhydrite were identified (Table 6).

\section{Conclusion}

The inorganic part of the both of the churches was made of gypsum and an iron-rich clay; and also, animal glue used as the binder of pastiglia. Linseed oil was probably employed as the glue in the gilding decorations. The gilding decorations of Vank cathedral also had a varnish layer that linseed oil was used for this aim. It seems that the structural and technical difference of these decorations in Isfahan Armenian and Islamic buildings at Safavid era, is the different phases of the clay of the pastiglias. 


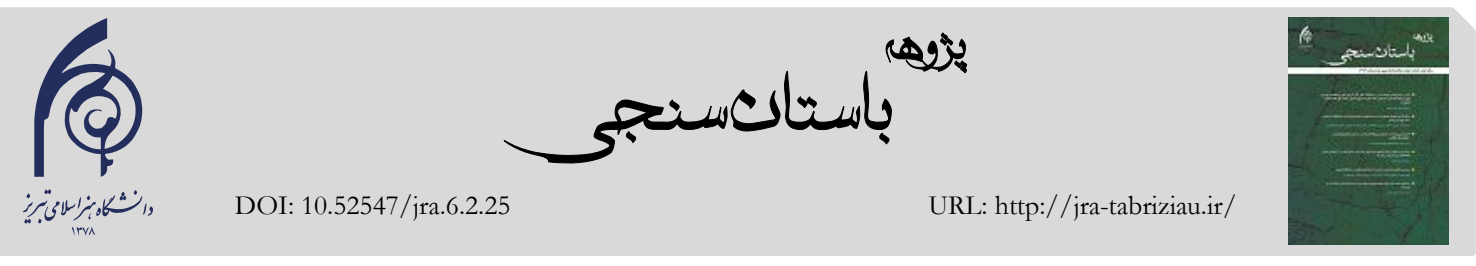

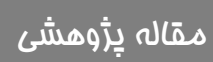

\section{ساختارشناسى لايهينى آرايلهاى طلاكارى كليساهاى وانك

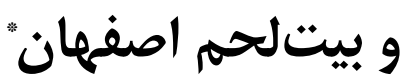

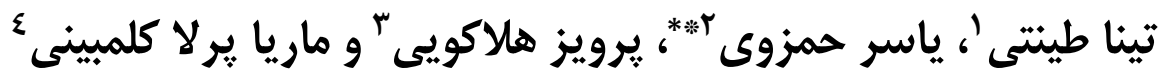

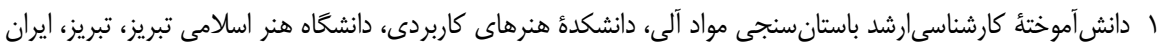

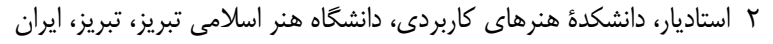

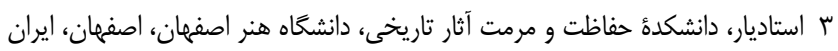

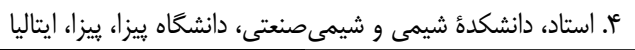

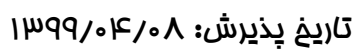

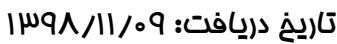

جكيده

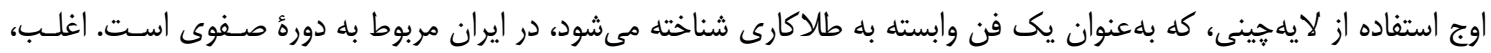

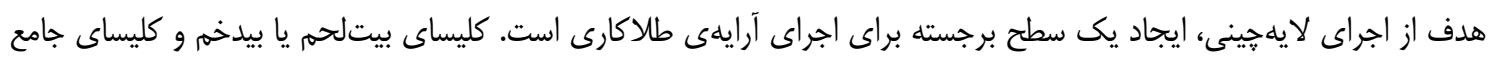

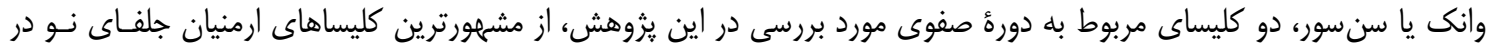

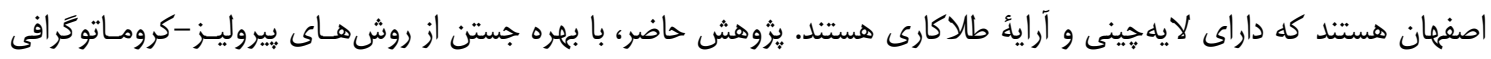

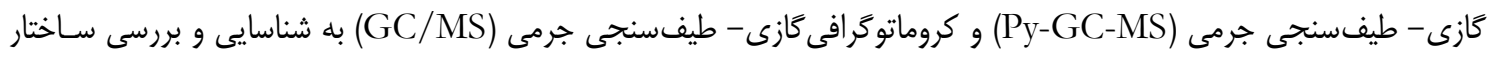

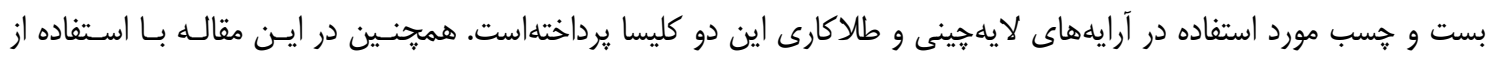

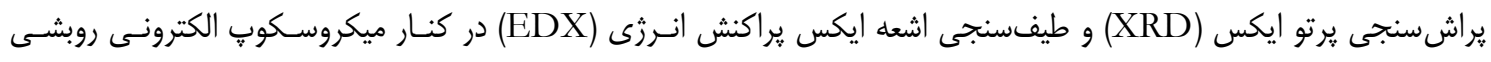

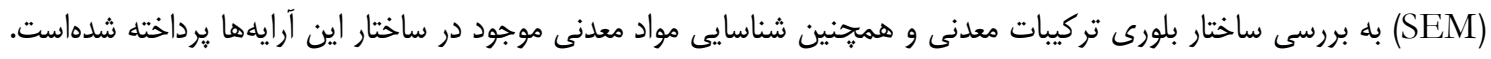

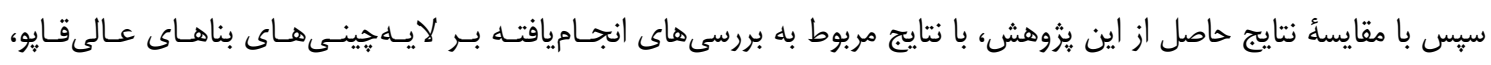

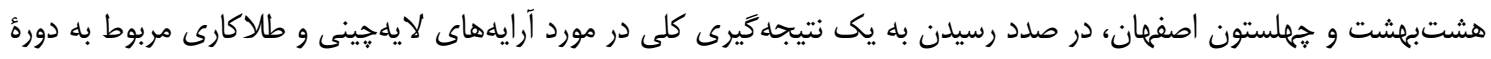

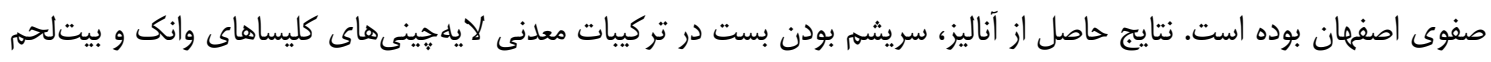

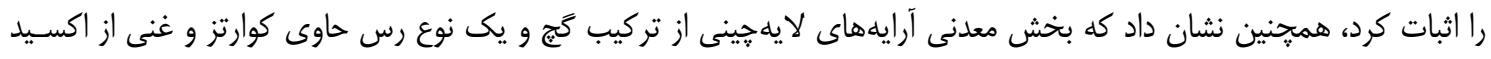

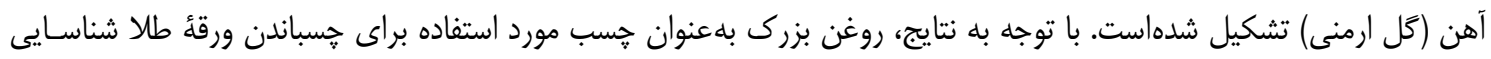

وازَّان كليدى: كليساى وانك، كليساى بيتلحم، لايهجينى، طلاكارى، صفوى

* اين مقاله بركرفته از يايان نامٔ كارشناسى ارشد رشتأ باستانسنجى تينا طينتى با عنوان لامطالعه ساختارى آرايههاى لايهجينى در كليسـاهاى

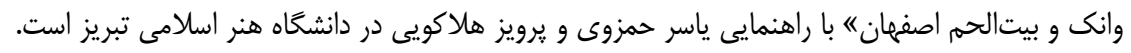

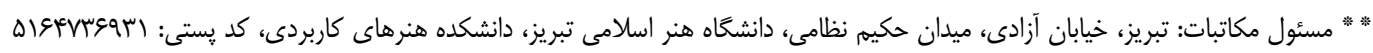

y.hamzavi@tabriziau.ac.ir يست الكترونيكى

Creative Commons Attribution License به Cبه مجله اجازه مى دهد مقاله جاب شده

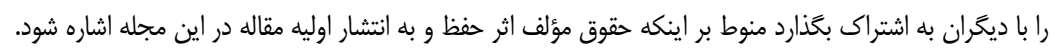


اصطلاح لايـه קينـى بـراى توصـيف نـوعى از تزيينـات

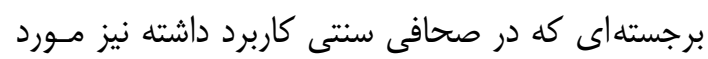

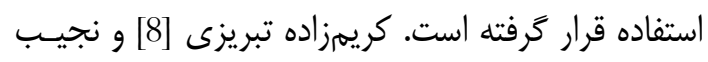

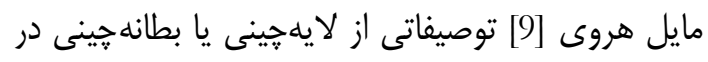

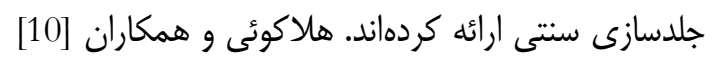

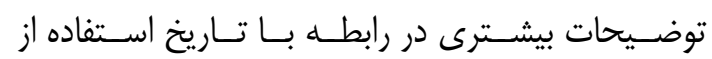
لايهجينى و وازمششناسى آن در ايران دادهاند.

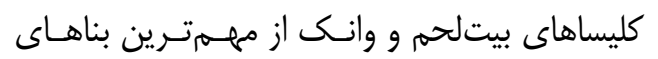

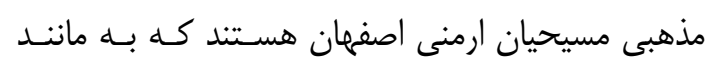

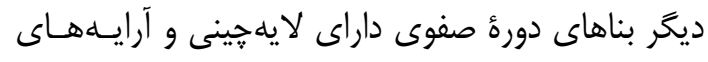

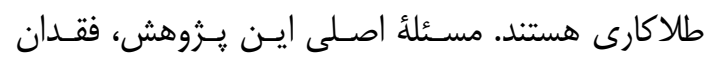

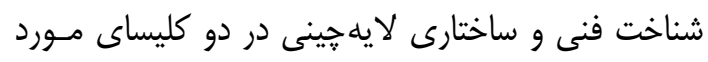

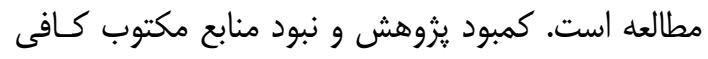

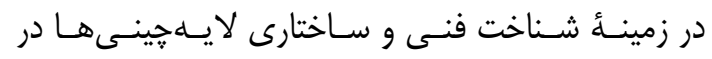

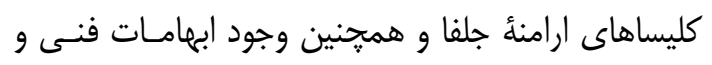
روشن نبودن خاستخاه و منشأ هنر ارامنأ جلفاى اصفهان وان إنهات

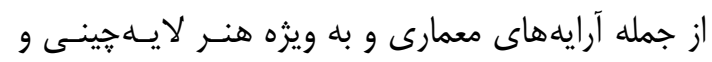

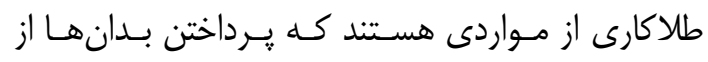

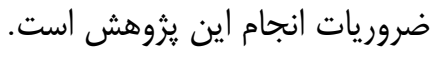

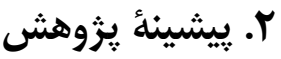

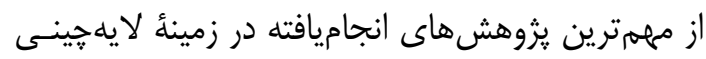

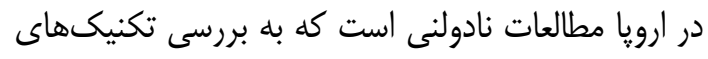

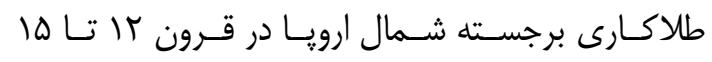

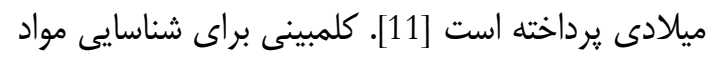

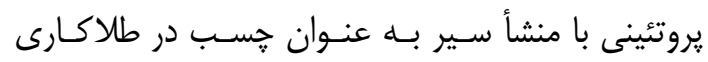

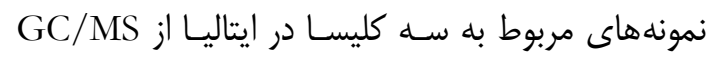

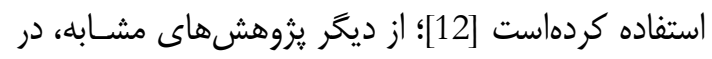

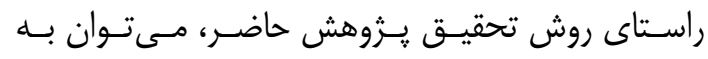

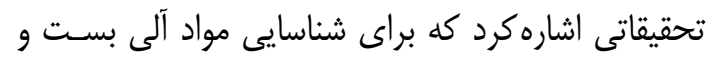

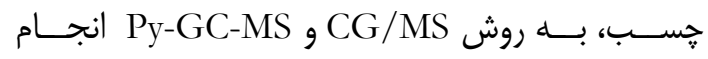

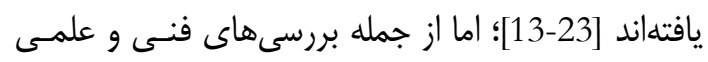

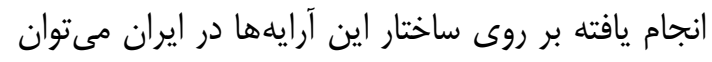

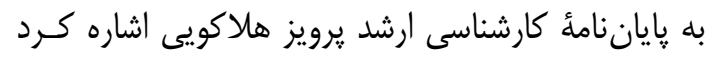

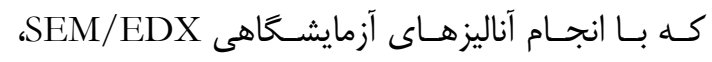

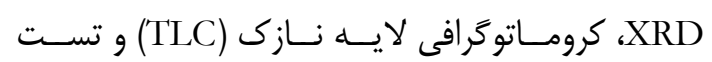

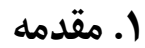

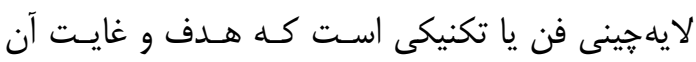

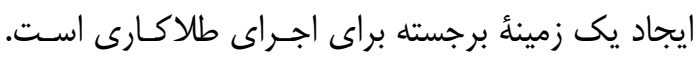

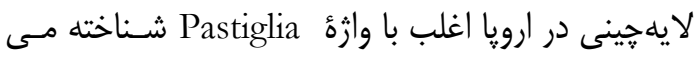

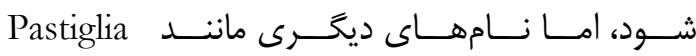
Applique ،Relieve en Stucco ،Yesería ‘Pastillaye ن نيـز بـراى سـطوح برجسـته مناسب براى طلاكارى مورد استفاده بوده است[1]]. وازٔه Pastiglia

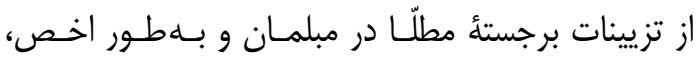
جعبههاى كوجى تزيينى نيز بهكار مىرفته است [2]. امـا

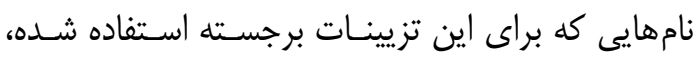

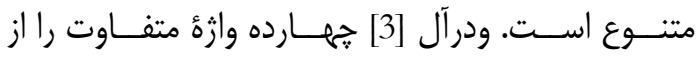

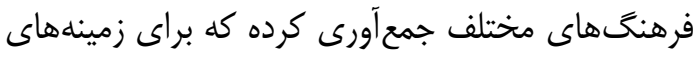

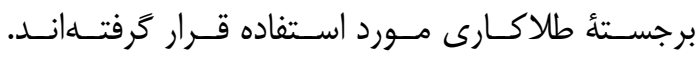

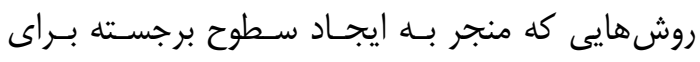

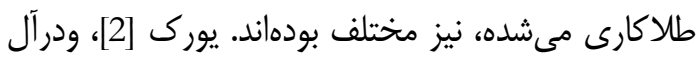

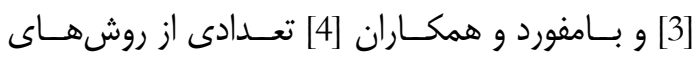

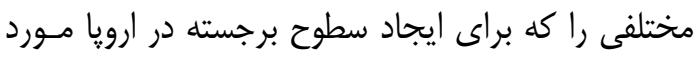

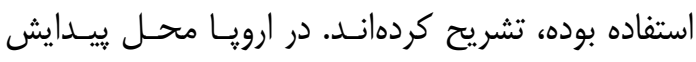

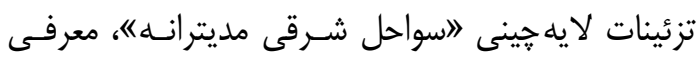

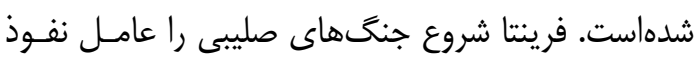

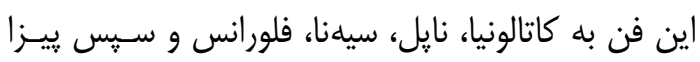

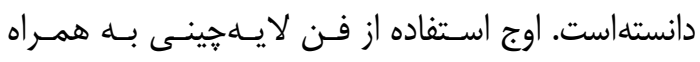

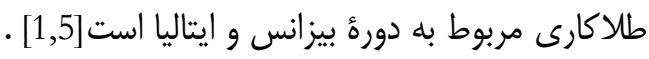

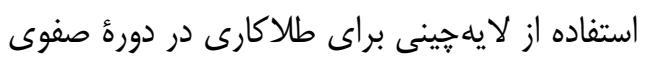

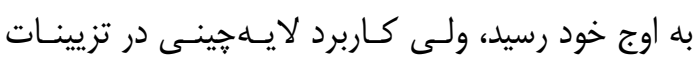

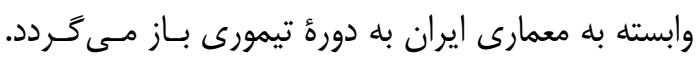

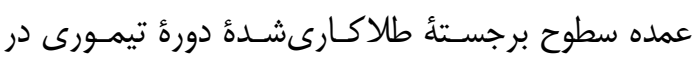

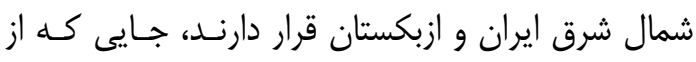

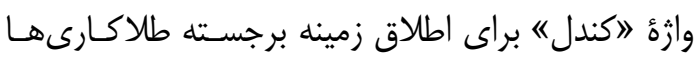

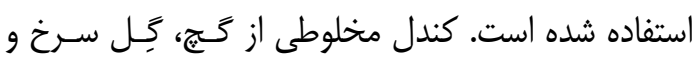

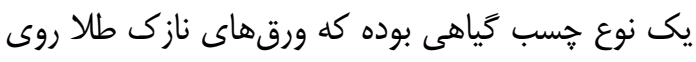

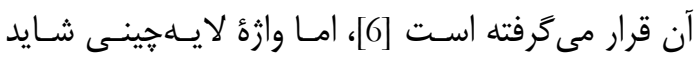

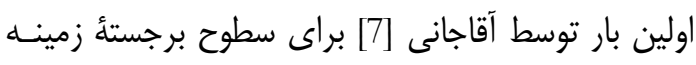

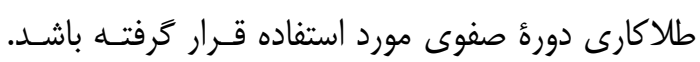


كليساى مجلل بنا شد [29]. با توجه بـه كتيبـهاى كـه در

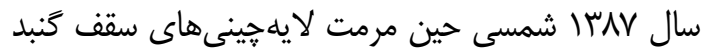

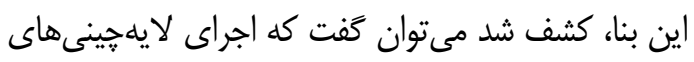

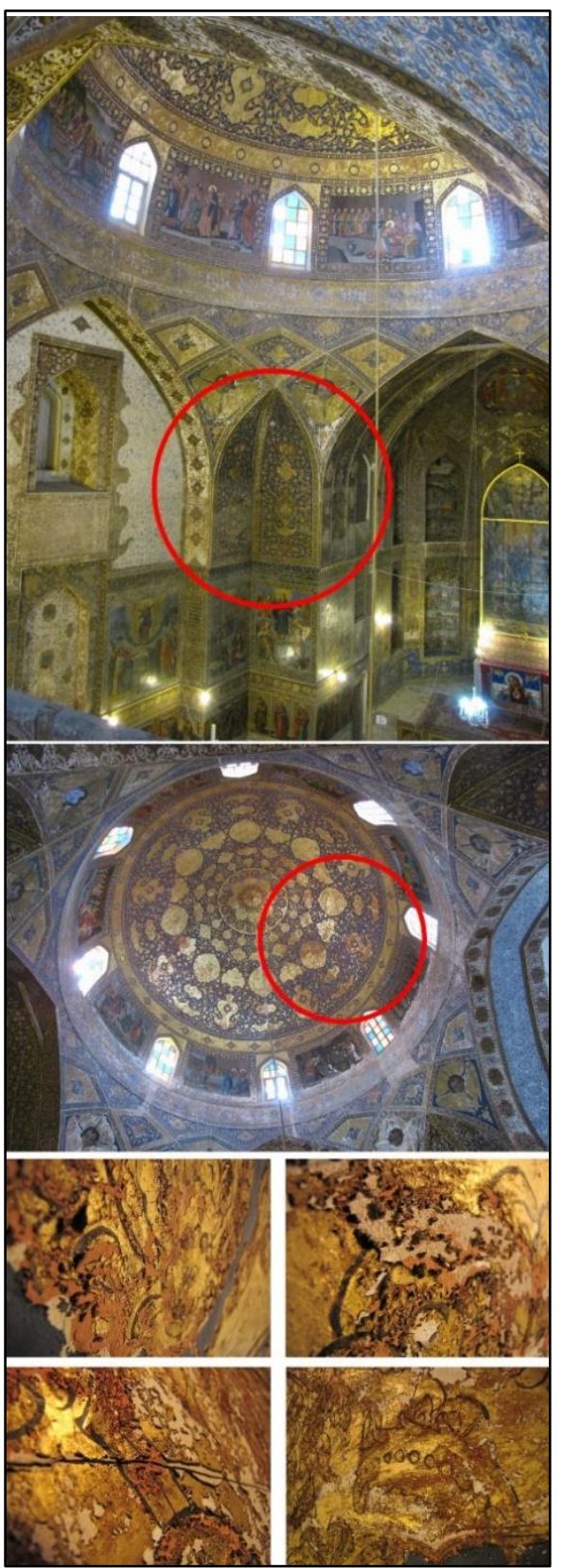

شكل ا: مجموعه تصاوير كليساى بيتلحم. تصوير بالا: محل نمونهبردارى نمونه 2010.B.1

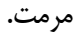

Fig. 1: (top, middle) General view from the dome chamber of the Bethlehem Church and location of sampling namely (top) 2016.B.2 and (middle) 2010.B.1 together with (four images at bottom) deteriorated pastiglia before restoration.
نين هيدرين، بر روى نمونسهـهـايى از بناهـاى عـالىقـايو،

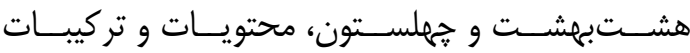

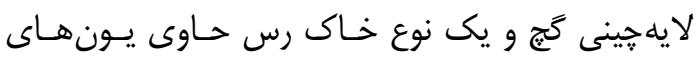
آهن، به همراه بست سريشم شناسايى كردهاسـت؛ نـوع

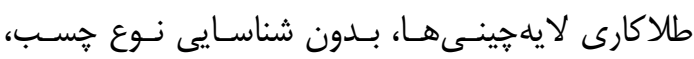

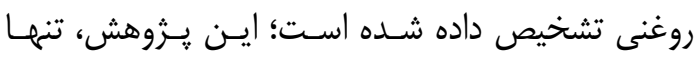

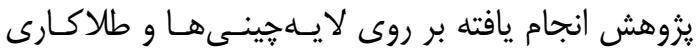
هاى دورة صفوى است [10].

"ا. معرفى بناهاى مورد مطالعه

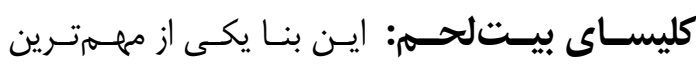

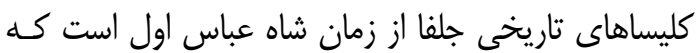
توسط خواجـهـ يطـروس، يكـى از تجــار ارامنـه، در سـال

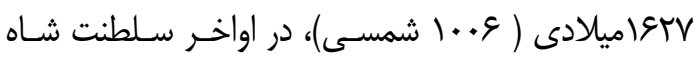
عباس اول يى ريزى شدهاست. ساخت اين كليسا، كـه در

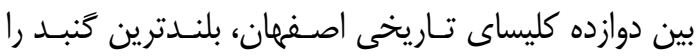

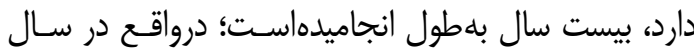

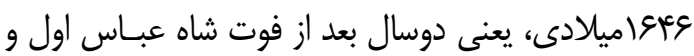

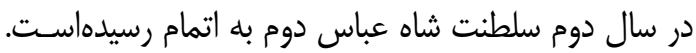

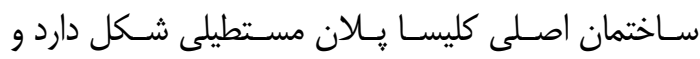

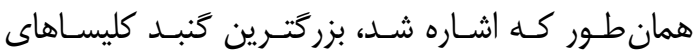
اصـفهران را در بخــش ميـانى خــودش دارد. ايـن بنـا در توسعههاى شهرى تغييرات زيادى كردهاست [24,25,26].

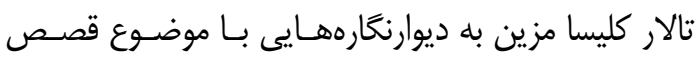

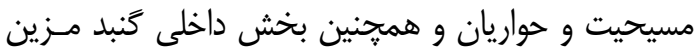

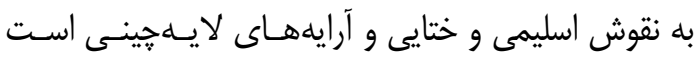
كليساى وانك: اين بنا در محلئ جلفاى اصـفهان واقع

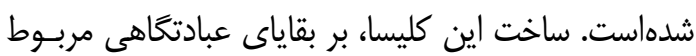

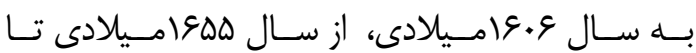

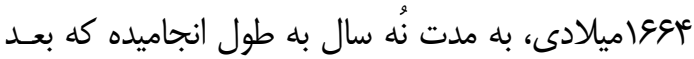

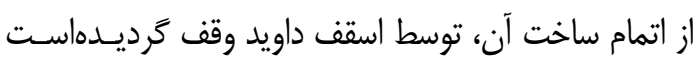
[26,27,28]. ارامنه پِّ از استقرارشان در جلفاى اصفهان،

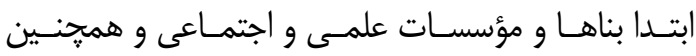

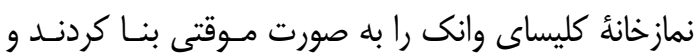

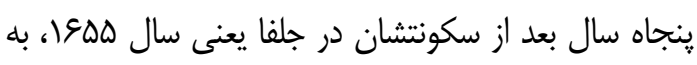

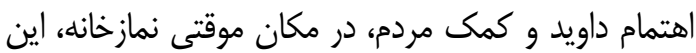


ع. مواد و روشها

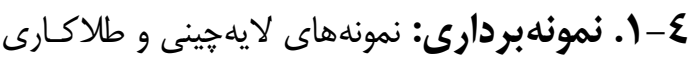

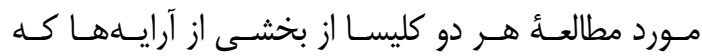

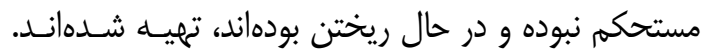

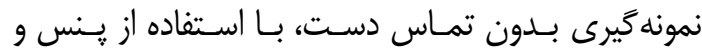

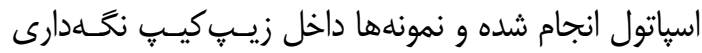

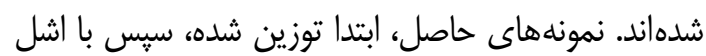

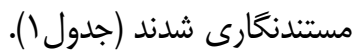

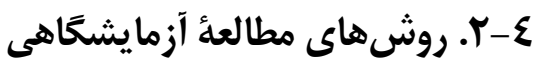

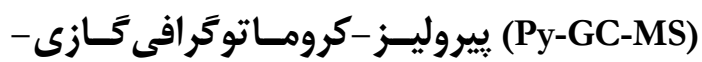
طيفسنجى جرمى: آناليز توسط يك دستخاه ييروليـزر multi-shot EGA/PY-3030D (Frontier Lab) ساخت زاين، جفت شده با دستخاه كرومـاتوكر افى

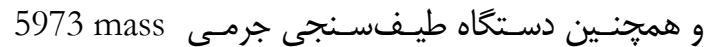
selective single quadrupole mass spectrometer ساخت امريكا انجام شد. (Agilent Technologies)

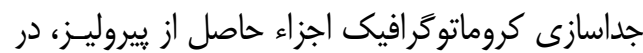

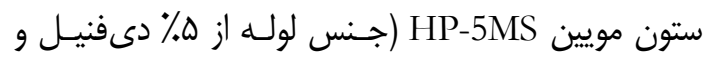

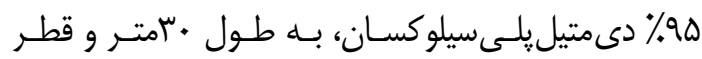

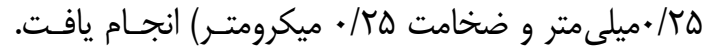

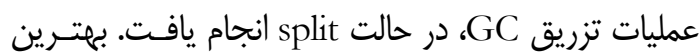
نتايج آناليزها در نسبت split • :1: حاصل شدند.

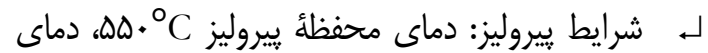

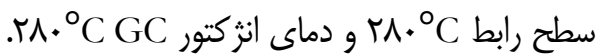

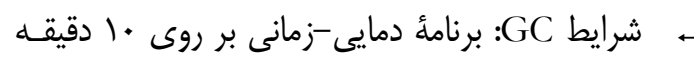
در

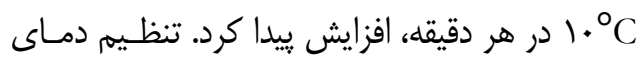

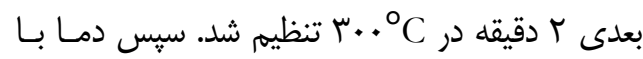

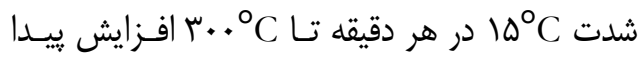

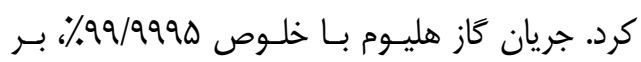

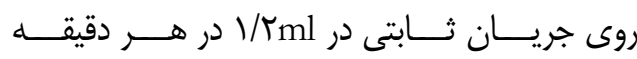

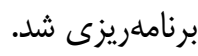
لـ شرايط MS: فشار الكتـرون يـونيزه ( El, 70eV) در

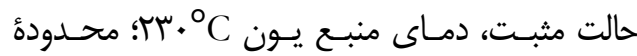

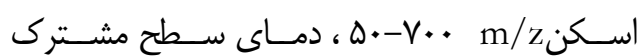
.$r \Lambda \cdot{ }^{\circ} \mathrm{C}$
آن تا سال Vو\& ام (يعنى سه سال بعد از اتمام ساخت بنـا) به طول انجاميده است [27] (شكل r).
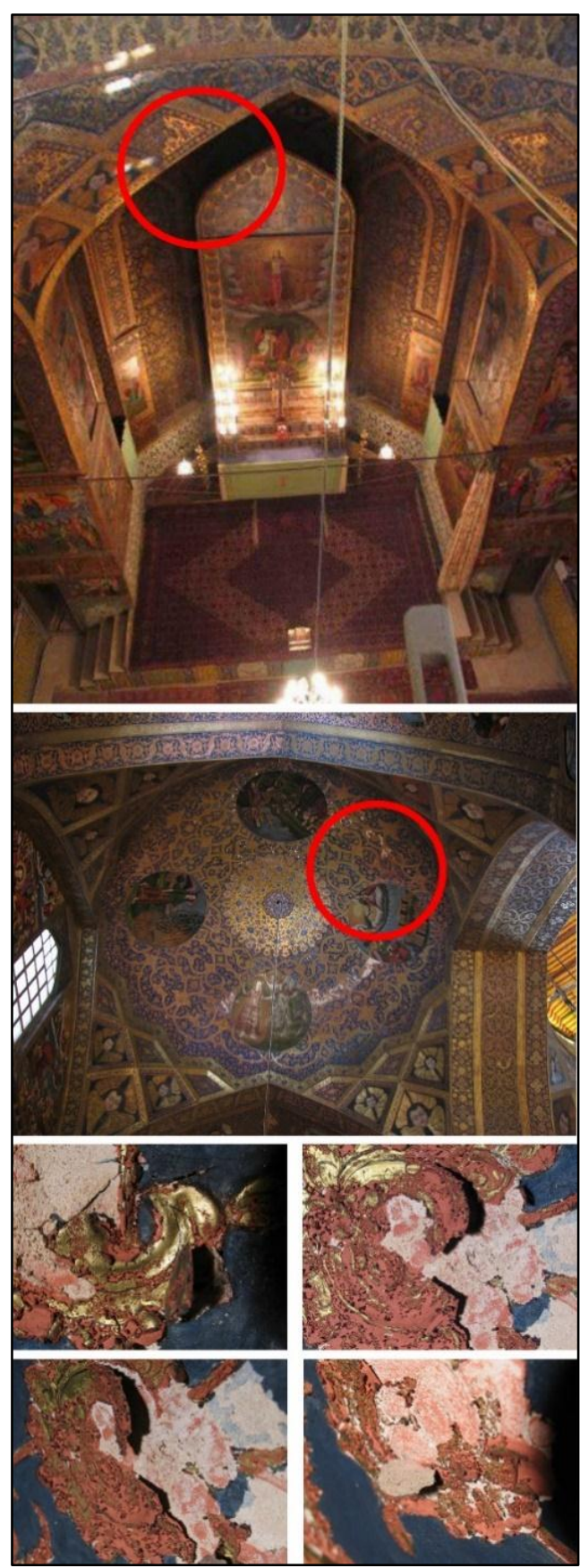

شكل ז: مجموعه تصاوير كليساى وانك. تصوير بالا: محل

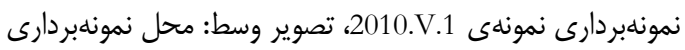

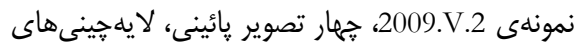
أسيبديدهى قبل مرمت.

Fig. 2: (top, middle) General view from the dome chamber of the Vank Cathedral and location of sampling namely (top) 2016.V.1 and (middle) 2010.V.2 together with (four images at bottom) deteriorated pastiglia before restoration. 


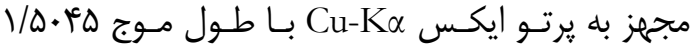

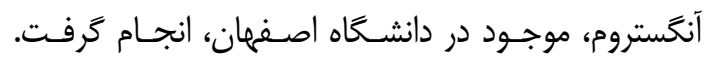

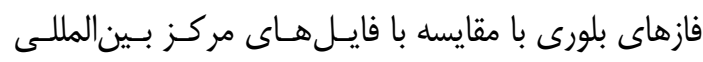
دادههاى يراش يرتو ايكس (ICDD PDF)، با نـرمافززار X'Pert HighScore Plus دستخاههاى كمكى: يك آون مايكروويو با مشخصات: MILS-1200 MEGA Milestone, FKV, Sorisole, Bergamo, Italy كه بــراى هيـدروليز مـواد بروتئينسى و يِيتيدى و همجنين بـراى صـابونى و نمكى كـردن مـواد

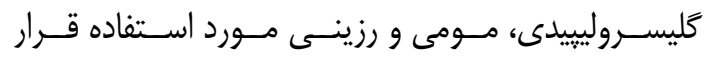
كرفتهاست.

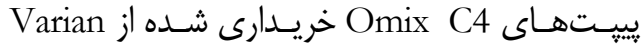

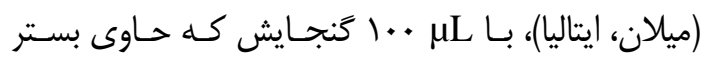
جامد به عنوان فاز استخراج كننده است.

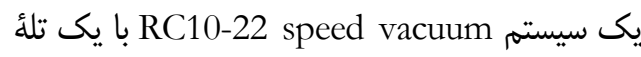

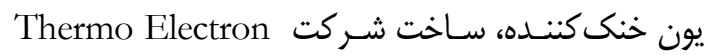
Crop (St. Herblain, France) محلولهاى آبى مورد استفاده قرار گرفتناست.

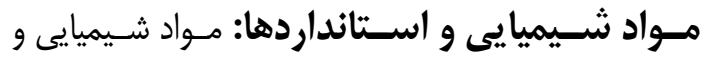
استانداردهاى مورد استفاده در روند شناسايى مواد آلى، در

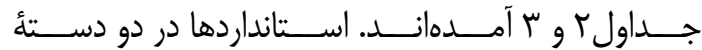
استانداردهاى داخلى تزريق و مشتقسـازى مـورد اسـتفاده

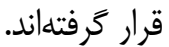

كروماتو (GC/MS) جرمى: آنـاليز در آزمايشـاه ديارتمـان شـيمى و شـيمى

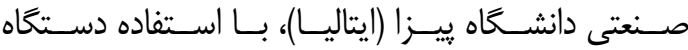

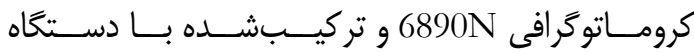
5973 mass selective single طيـفسـنجى جرمى تروئ quadrupole mass spectrometer (Agilent Technologies)

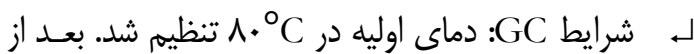

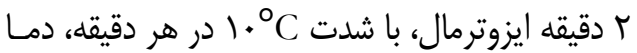

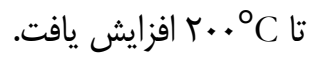

لـ شرايط MS: فشار الكترون يـونيزه ( El, 70eV) در

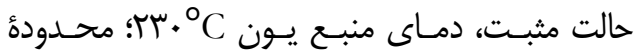

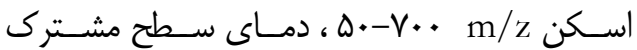

$$
. r \Lambda \cdot{ }^{\circ} \mathrm{C}
$$

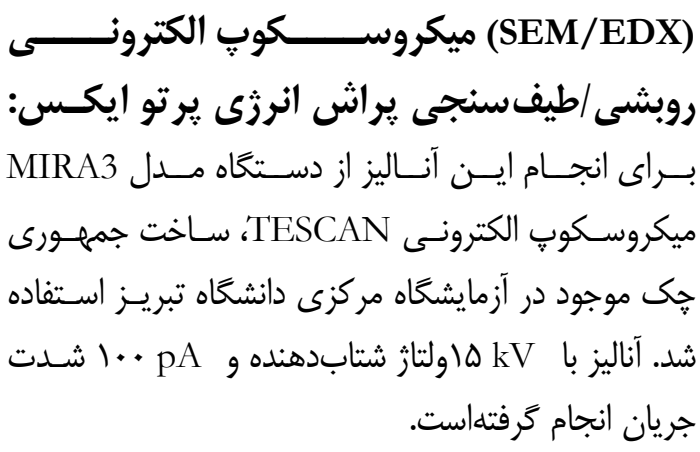
يراش اشعة ايكـس : آناليزهـا بـا دسـتخاه

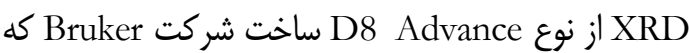

جدول (: مشخصات نمونهها

Table 1:Specification of samples

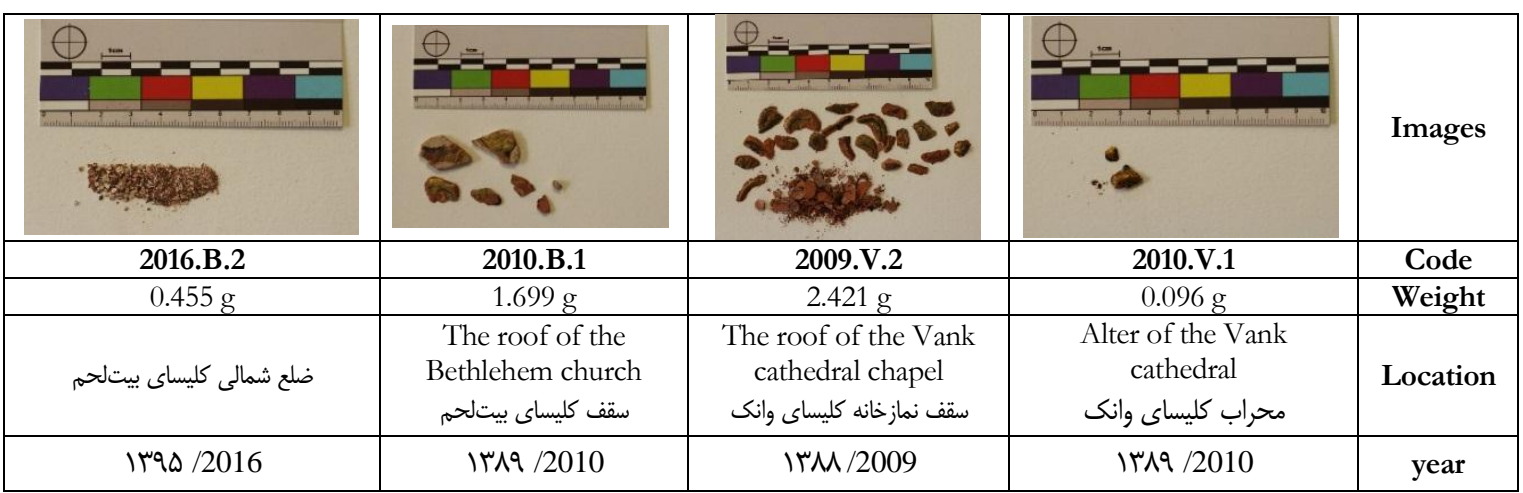


جدول ז: مواد شيميايى مورد استفاده

Table 2: Chemical reagents

\begin{tabular}{|c|c|}
\hline Reagent & Purchased from... \\
\hline Trifluoracetic acid ; 99\% & Fluka \\
\hline Anhydrous pyridine & Fluka \\
\hline ETSH; $99.5 \%$ & Sigma-Aldrich \\
\hline Sodium azide; $99.5 \%$ & Sigma-Aldrich \\
\hline $\begin{array}{c}\text { BSTFA with and without } 1 \% \\
\text { trimethylchlorosilane }\end{array}$ & Sigma-Aldrich \\
\hline $\begin{array}{c}\text { MTBSTFA }+1 \% \\
\text { trimethylchlorosilane }\end{array}$ & Sigma-Aldrich \\
\hline triethylamine & Sigma-Aldrich \\
\hline
\end{tabular}

جدول ب: استانداردها

Table 3: Standards

\begin{tabular}{|c|c|c|}
\hline Solution & Contents & Usage \\
\hline $\begin{array}{c}\text { Amino acid solution in } \\
0.1 \mathrm{M} \mathrm{HCl}\end{array}$ & $\begin{array}{c}12.5 \mu \mathrm{mol} / \mathrm{ml} \text { of Pro \& Hyp }+2.5 \mu \mathrm{mol} / \mathrm{ml} \text { ofAsp, Glu, Ala, } \\
\text { arginine, cysteine, Phe, Gly, hydroxylysine, Ile, Leu, Lys, Met, Ser, } \\
\text { Tyr, threonine, Val }\end{array}$ & \\
\hline $\begin{array}{l}\text { Solution of fatty and } \\
\text { dicarboxylic acids in } \\
\text { acetone }\end{array}$ & $\begin{array}{l}\text { Lauric acid }(0.24 \mathrm{mg} / \mathrm{g}) \text {, suberic acid }(0.27 \mathrm{mg} / \mathrm{g}) \text {, azelaic acid }(0.28 \\
\mathrm{mg} / \mathrm{g}), \text { myristic acid }(0.25 \mathrm{mg} / \mathrm{g}), \text { sebacic acid }(0.3 \mathrm{mg} / \mathrm{g}), \text { palmitic } \\
\text { acid }(0.25 \mathrm{mg} / \mathrm{g}) \text {, oleic acid }(0.51 \mathrm{mg} / \mathrm{g}) \text {, stearic acid }(0.51 \mathrm{mg} / \mathrm{g})\end{array}$ & \\
\hline $\begin{array}{l}\text { Norleucine solution in } \\
\text { bidistilled water }\end{array}$ & $138.66 \mu \mathrm{g} / \mathrm{g}$ & $\begin{array}{l}\text { Derivatization internal } \\
\text { standard } \\
\text { For amino acids }\end{array}$ \\
\hline $\begin{array}{c}\text { Tridecanoic acid } \\
\text { solution in isooctane }\end{array}$ & $135.48 \mu \mathrm{g} / \mathrm{g}$ & $\begin{array}{l}\text { Derivatization internal } \\
\text { standard for lipid-resinous } \\
\text { fraction }\end{array}$ \\
\hline $\begin{array}{l}\text { Hexadecane solution } \\
\text { in isooctane }\end{array}$ & $80.34 \mu \mathrm{g} / \mathrm{g}$ & Injection internal standard \\
\hline
\end{tabular}

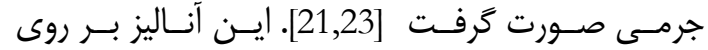

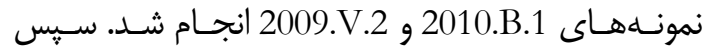

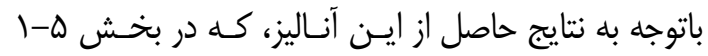

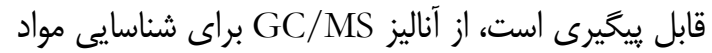

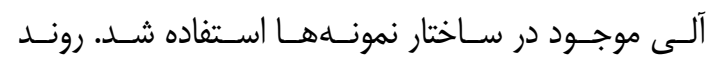

$$
\begin{aligned}
& \text { ع-س. روند آزمايشًَاهى انجام آناليزها: باتوجه بــه }
\end{aligned}
$$

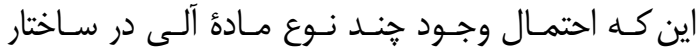

$$
\begin{aligned}
& \text { نمونههاى لايهجينى ها و طلاكارىها وجود داشت، در ابتدا }
\end{aligned}
$$

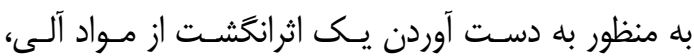

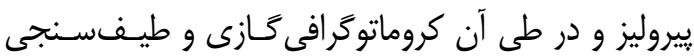

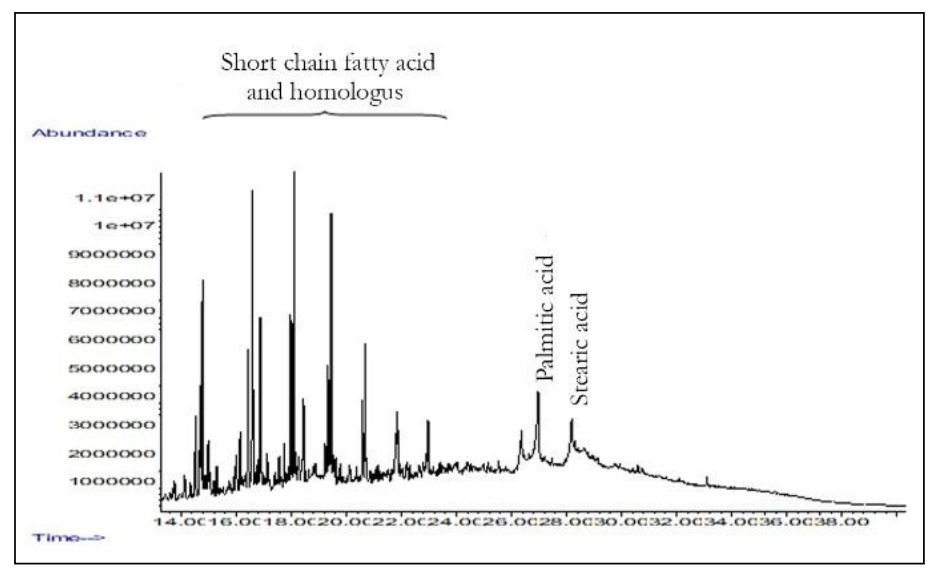

شكل سّ: كروماتوكرام 2009.V.2 Py-GC-MS. اين طيفها بدون اضافه كردن عامل مشتقساز به نمونه حاصل شدهاند.

Fig. 3: Py-GC-MS Chromatogram of 2009.V.2, without derivatization agent.

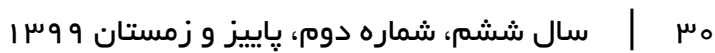


اسـتئاريكاسـيد و تركيبـات مشـابهشـان باشــند؛ البتـه،

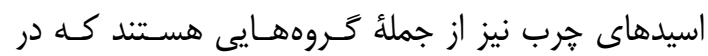

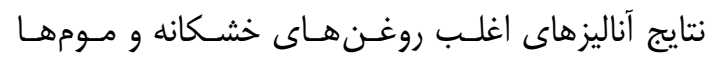

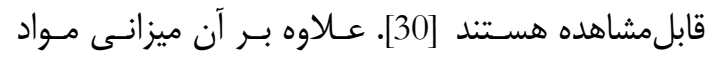

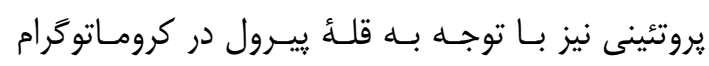

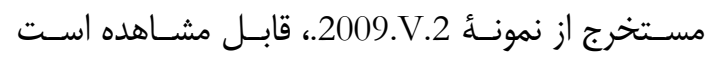

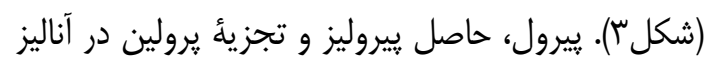

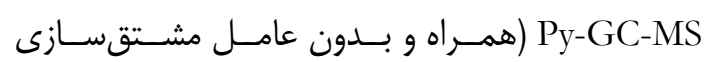

(15) است (15DS

\section{ه-r. نتايج آناليز GC/MS در شناسـايـ مــواد}

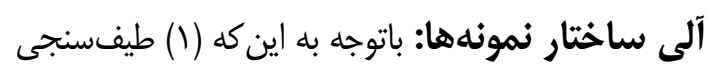

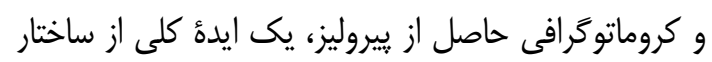

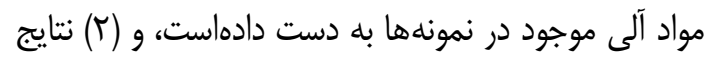

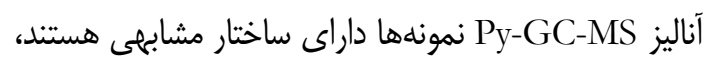

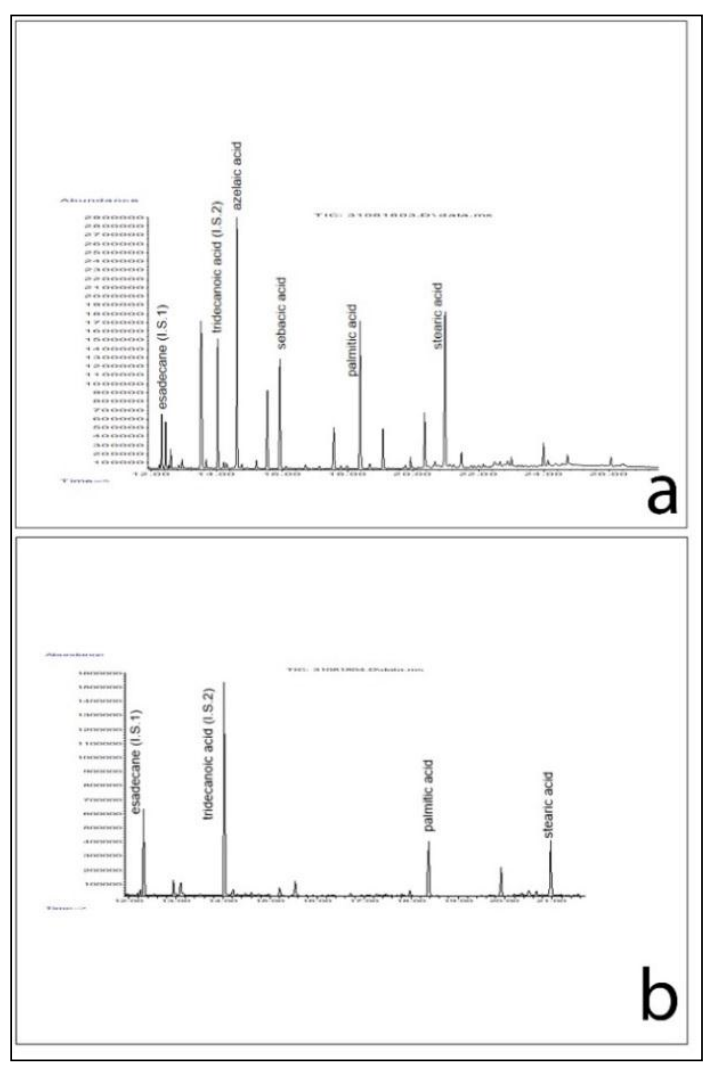

شكله: كروماتوگرام GC/MS مواد يروتئينى. كروماتو گرامه: نمونهُ

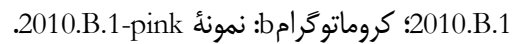

Fig. 5: GC/MS Chromatogram of proteinaceous materials. Chroma. a: 2010.B.1; Chroma. b: 2010.B.1-pink.

w سال ششم، شماره دوم، پياييز و زمستان 9 وس |

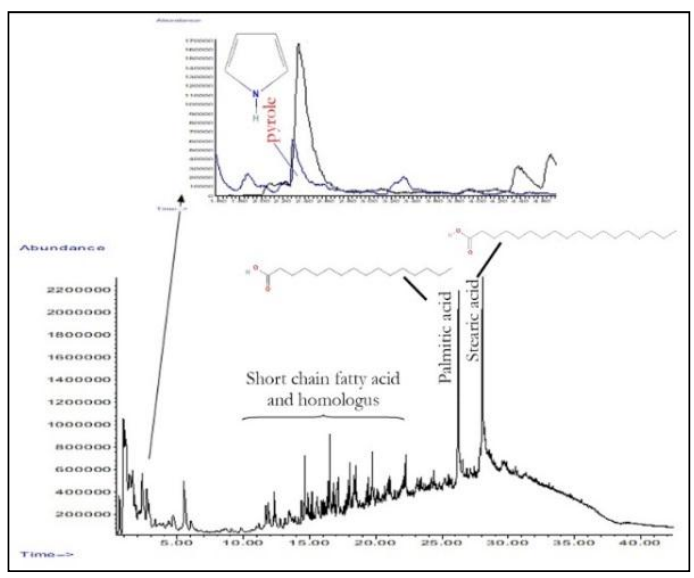

شكل ثٔ: كروماتوگرام 2010.B.1 Py-GC-MS. اين طيفها با اضافه

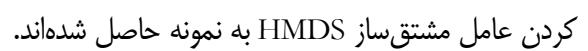

Fig. 4: Py-GC-MS Chromatogram of 2010.B.1, with HMDS derivatization agent.

آناليز GC/MS انتخاب شده، بر اساس استخراج با محلول آمونياك است؛ در اين روند، نيازى به جداسازى اولئه مـواد التهاد

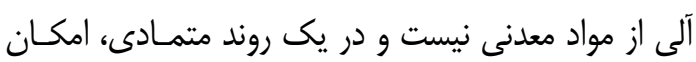

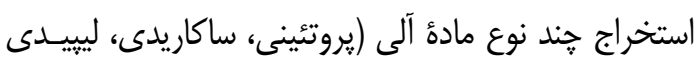

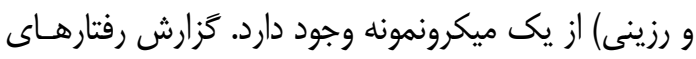
شيميايى انجام يافته بر روى نمونهها در رفرنس 14 قابـل ييخيرىاست.

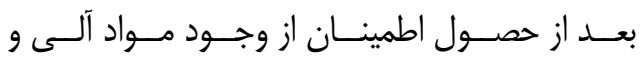

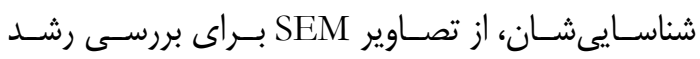

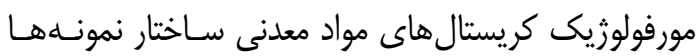

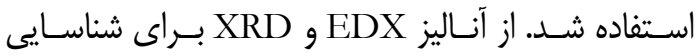

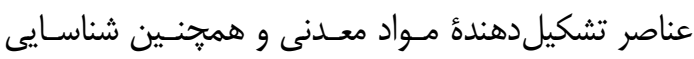
فازى اين مواد استفادهشد.

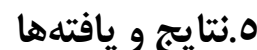

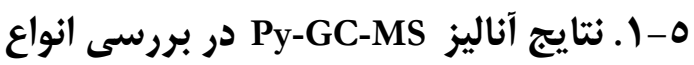

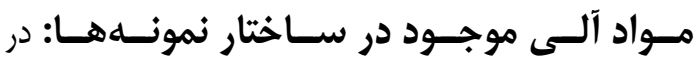

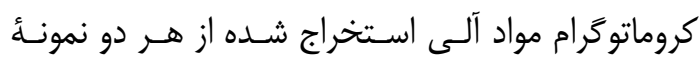
منتخب (2009.V.2, 2010.B.1)، قله هاى يالميتيكاسيد

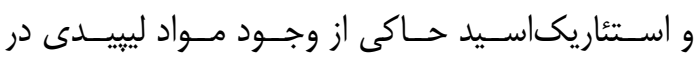

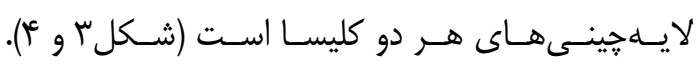
اسيدهاى خرب و تركيبات مشابه، مى توانند حاصل رونسـ

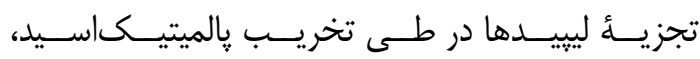


كلوتاميكاسيد. باتوجه به شكلع، كه كروماتوكرام مـواد لييبدى و رزينى استخراج شده از نمونههاى 2010.B.1 و 2010.B.1-pink كروماتو گرافى به ترتيب هكَز ادكان، ترى دكانوئيكاسـيلد،

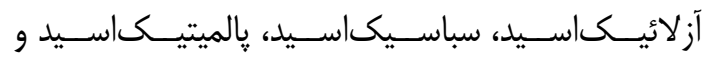
استئاريكاسيد است. باتوجه به كروماتوكرامهاى حاصـل

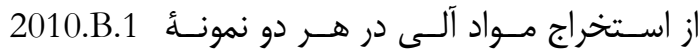

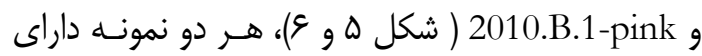
مواد يروتئينى و مواد لييبيدى هستند.

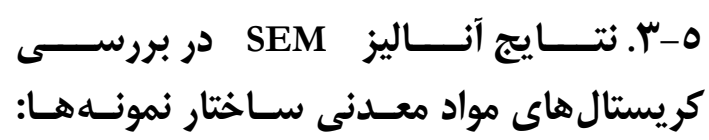

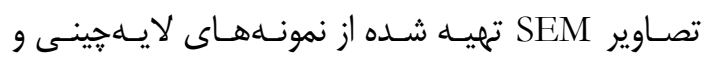

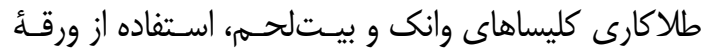

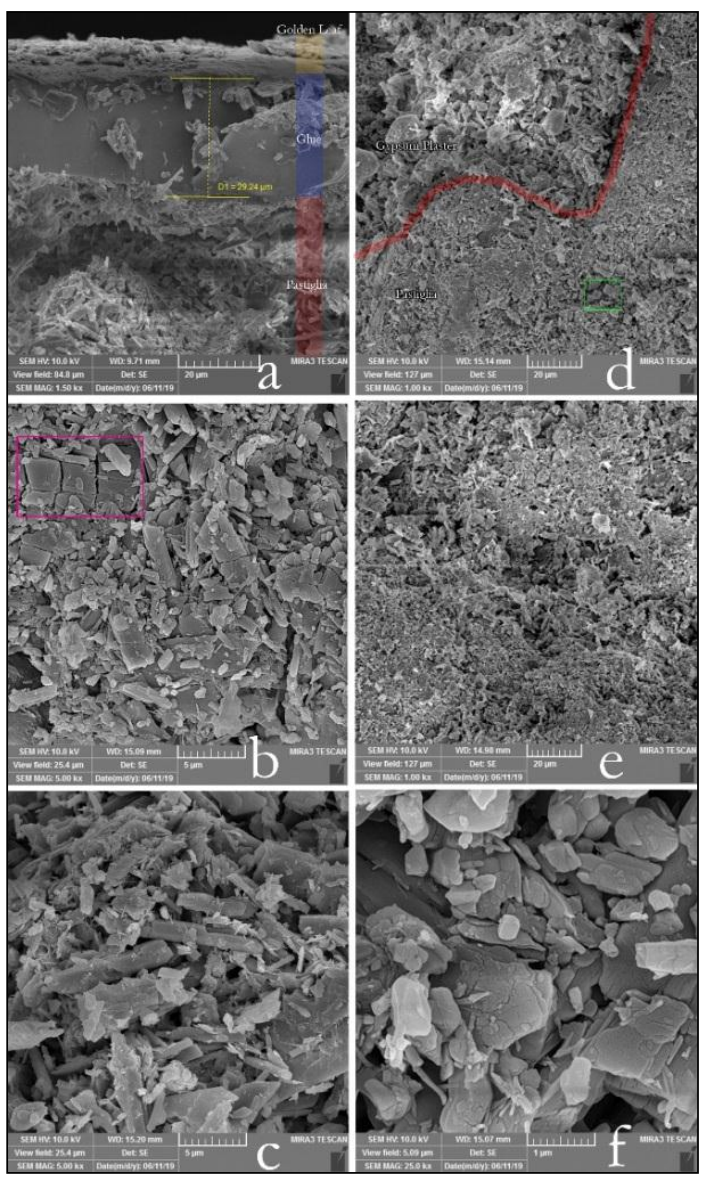

شكل V: تصاوير SEM تهيه شده از نمونههاى كليساى بيتلحم. Fig. 7: SEM Pics of samples of Bethlehem church.

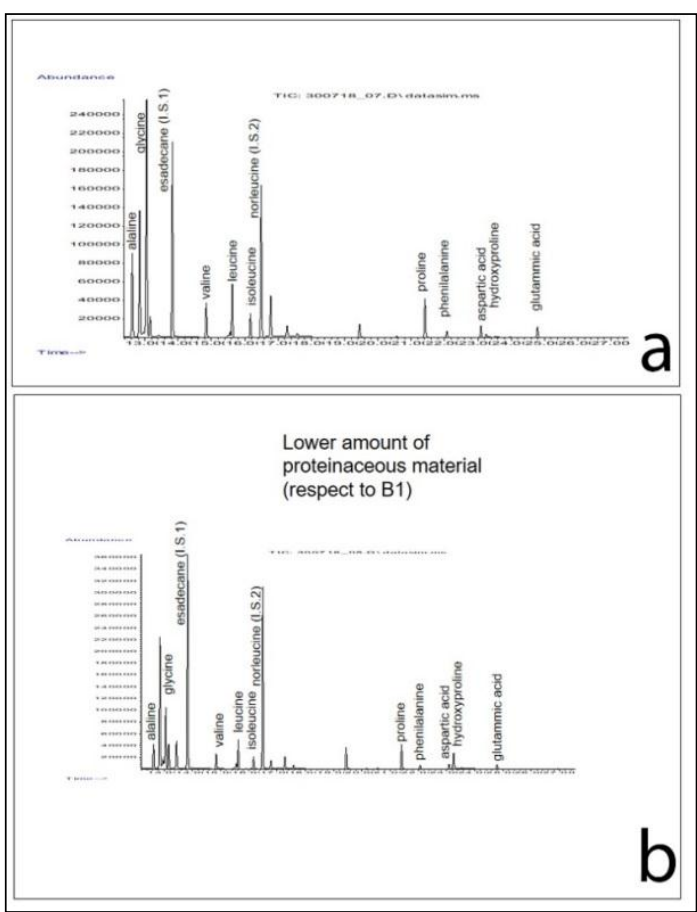

شكل ع: كروماتوگرام GC/MS مواد لييبدى. كروماتوكرامa: نمونئ 2010.B.1

Fig. 6: GC/MS Chromatogram of lipidic materials. Chroma. a: 2010.B.1; Chroma. b: 2010.B.1-pink.

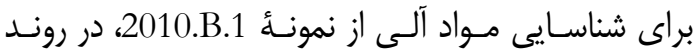
GC/MS استفاده شد. جداسازى كروماتوكرافيك بر روى نمئس

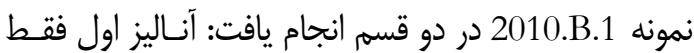
بر روى بخش لايهجينى نمونه (با كــ 2010.B.1-pink)،

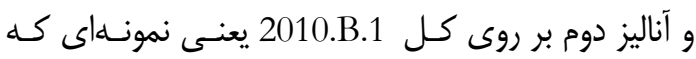

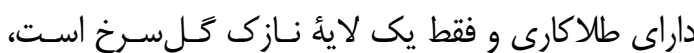

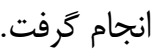

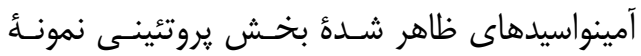

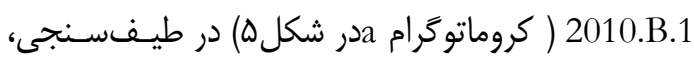
به ترتيب خروج و ظهور، به اين صـورت اسـت: آلانسين،

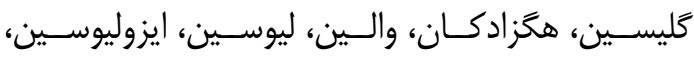

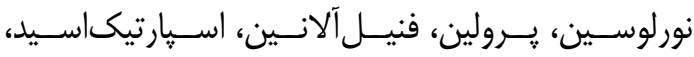

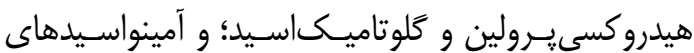

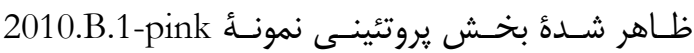

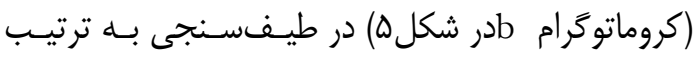
خروج و ظهور به اين صـورت اسـت: آلانسين، كليسـين،

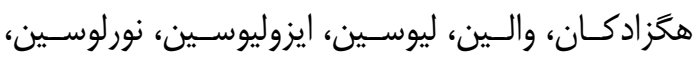

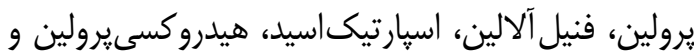

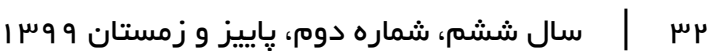


ه-ع. نتايج آنـاليز EDX در شناسـايى عناصـر موجود در ساختار مواد معدنى نمونهها: باتوجه بــه نتايج درج شده در جدول أ، بيشترين درصدهاى وزنى، هم

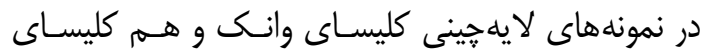

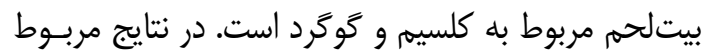

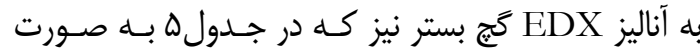

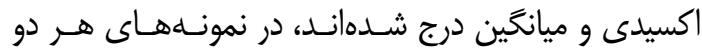
كليسا، بيشترين درصد را در بين عناصـر شناسـايى شـده،

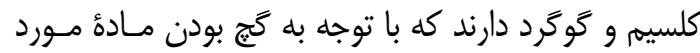

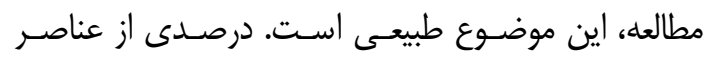
منيزيه، آلومينيوم، سيلسيوم، كلر، يتاسيه، سديم و آهن نيز آنيز،

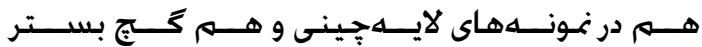
شـناسـايس شـدهاند.

ه-0. نتايج آنـاليز XRD در شناسـايى فـازى مواد معدنى نمونهها: براى شناسايى كيفى فازهـاى

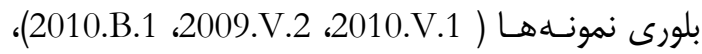
اين آناليز انجام كرفت. فاز غالب نمونهها زييس و كوارتز

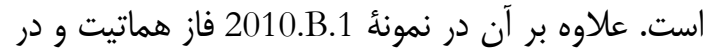
نمونه 2009.V.2 فاز انيدريت نيز مشاهده شدهاست.

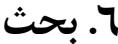
7-1. بحث در نتايج مربـوط بـهـ مــواد آلـى: در

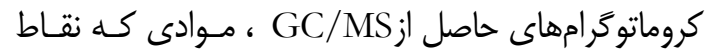

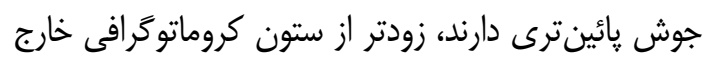

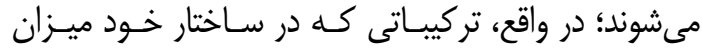
كربن و قطبيت كمترى داشتهباشند، زودتر در كروماتوكرام ظاهر مىشوند [14-13]. باتوجه به اين كه آمينواسيدهاى شناسايى شده در هـر

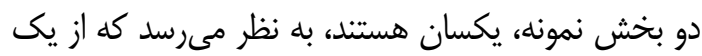

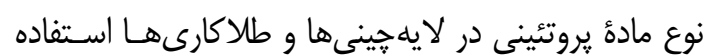
شدهاست. در شناسـايى مـواد آلى يروتئينـى موجـود در نمونهها از روش استفاده از ماركر و شاخص مـواد اسـتفاده شدهاست. ميزان زياد كليسين شاخص كلازن و يـرولين و هيدروكسى يرولين، شـاخصهـاى شناسـايى سريشـم در

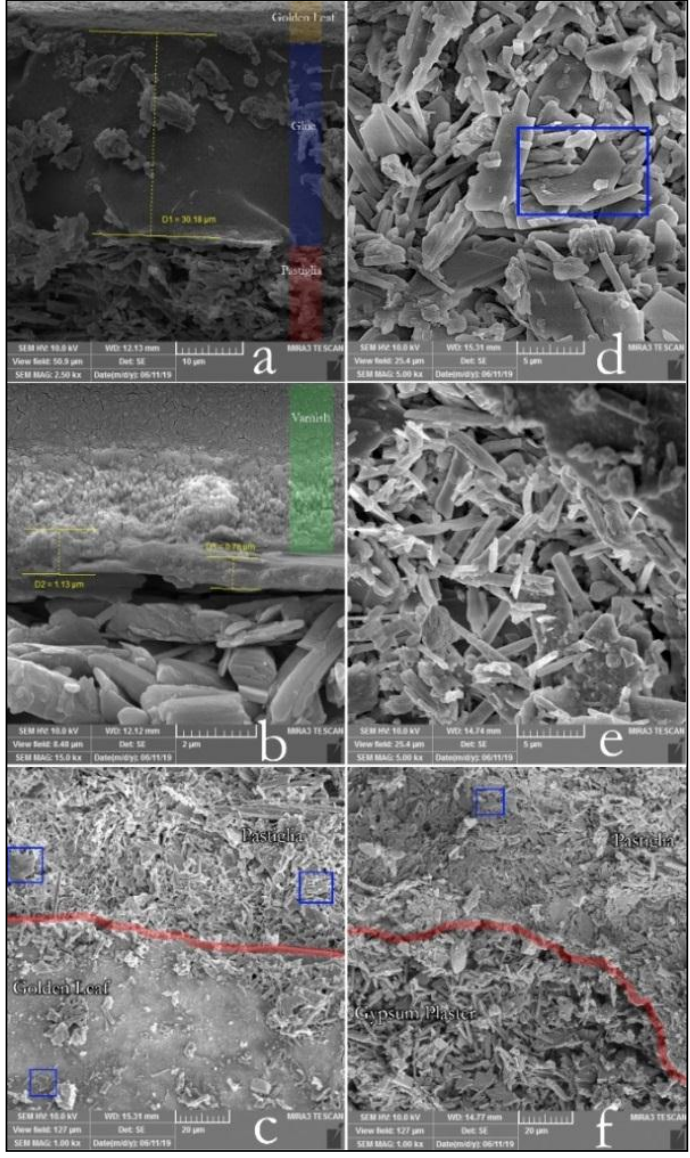

شكل ᄉ: تصاوير SEM تهييه شده از نمونههاى كليساى وانك. Fig. 8: SEM Pics of samples of Vank Cathedral

طلا در طلاكارى و وجود لايئ جسب در بين ورقأُ طلاو و لايهجينى را تأييد كردند (تصاوير a از شكلهاى لو و م).

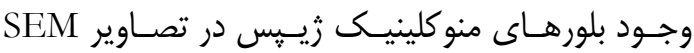
نمونههاى هر دو بنا قابل مشاهده است (تصاويرc، d، d، شكل \و ^). باتوجه به تصاوير، كريستالهاى موجود در

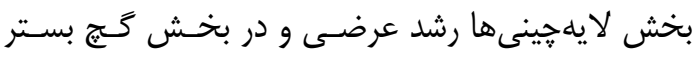

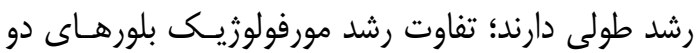
بخش لايهجينى و كج بستر در تصاويرى كه از مرز ايـن

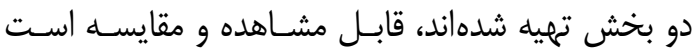

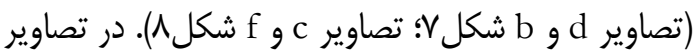

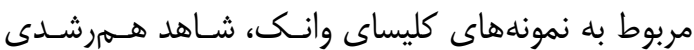
بلورهاى منوكلينيك زيبس هستيم؛ اين همرشدى كه به به صورت دوقلويى انعكاسى (دوقلويى دميرستويى) است، از ازئين

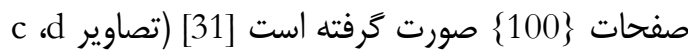
وf شكلم كادرهاى آبى). 
جدول EDX عناصر شناسايى شده از بخش لايهجينى نمونهها به روش

Table 4: Identified elements in Pastiglia part of samples with EDX analysis

\begin{tabular}{|c|c|c|c|c|c|c|c|c|c|c|}
\hline \multicolumn{2}{|c|}{ Ox. Form Elem. } & $\mathrm{Na}_{2} \mathrm{O}$ & $\mathrm{MgO}$ & $\mathrm{Al}_{2} \mathrm{O}_{3}$ & $\mathrm{SiO}_{2}$ & $\mathrm{SO}_{3}$ & $\mathbf{K}_{2} \mathrm{O}$ & $\mathrm{CaO}$ & $\mathrm{Fe}_{2} \mathrm{O}_{3}$ & $\mathrm{Cl}$ \\
\hline \multirow{2}{*}{ Vank } & $\overline{\boldsymbol{X}}$ & n.d & 1.38 & 3.53 & 8.84 & 46.52 & 1.14 & 32.75 & 4.46 & 1.38 \\
\hline & $\mathbf{S}$ & - & 0.64 & 0.77 & 3.23 & 1.98 & 0.24 & 1.78 & 1.40 & 0.51 \\
\hline \multirow{2}{*}{ Bethlehem } & $\bar{X}$ & 0.93 & 1.31 & 5.94 & 12.77 & 42.23 & 1.51 & 30.34 & 5.06 & 0.45 \\
\hline & $\mathrm{S}$ & 0.63 & 0.45 & 0.66 & 1.96 & 3.70 & 0.34 & 0.55 & 0.38 & 0.33 \\
\hline \multicolumn{11}{|c|}{ 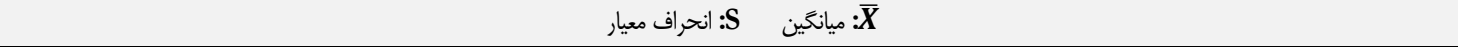 } \\
\hline
\end{tabular}

جلدوله: عناصر شناسايى شده از بخش گج بستر نمونهها به روش EDX

Table 5: Identified elements in Gypsum part of samples with EDX analysis

\begin{tabular}{|c|c|c|c|c|c|c|c|c|c|c|}
\hline \multicolumn{2}{|c|}{ Ox. Form Elem. } & $\mathrm{Na}_{2} \mathrm{O}$ & $\mathrm{MgO}$ & $\mathrm{Al}_{2} \mathrm{O}_{3}$ & $\mathrm{SiO}_{2}$ & $\mathrm{SO}_{3}$ & $\mathrm{~K}_{2} \mathrm{O}$ & $\mathrm{CaO}$ & $\mathrm{Fe}_{2} \mathrm{O}_{3}$ & $\mathrm{Cl}$ \\
\hline \multirow{2}{*}{ Vank } & $\bar{X}$ & n.d. & 1.29 & 3.55 & 9.87 & 45.83 & 0.87 & 36.16 & 1.43 & 0.95 \\
\hline & $\mathbf{S}$ & - & 0.02 & 2.45 & 9.88 & 13.16 & 0.65 & 0.64 & 0.87 & 0.95 \\
\hline \multirow{2}{*}{ Bethlehem } & $\bar{X}$ & 0.56 & 0.63 & 1.47 & 3.07 & 55.58 & 0.34 & 37.61 & 0.45 & 0.23 \\
\hline & $\mathbf{S}$ & 0.40 & 0.20 & 0.48 & 1.87 & 1.33 & 0.20 & 0.67 & 0.18 & 0.16 \\
\hline
\end{tabular}

Xدول ع. فازهاى شناسايى شده به روش XRD

Table 6: Identified phases with XRD analysis

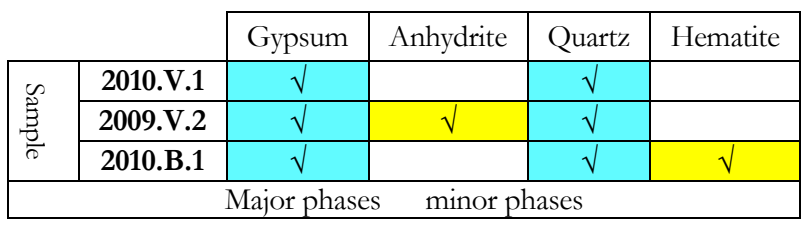

انواع كاربردهاى آن اشاره شدهاست [34]. باتوجه به كربوكسـيليكاسـيدهـاى اسـتخراج شـده،

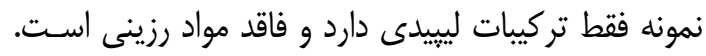

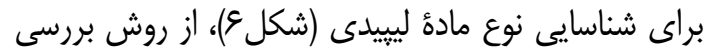

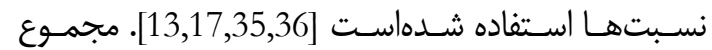

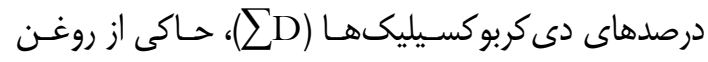

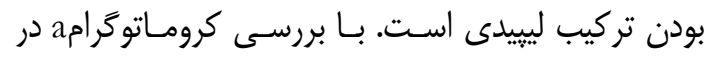

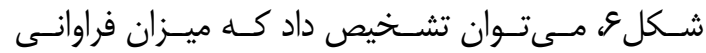

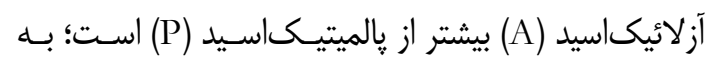

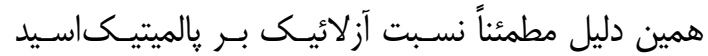

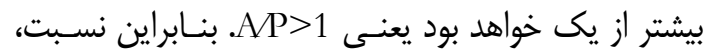
نتيجه حاصل مىشود كه روغن موجود در سـاختار نمونسه،

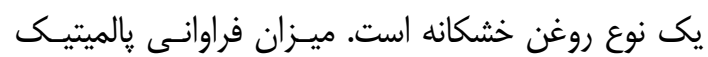

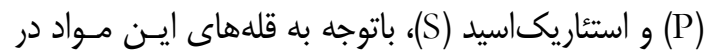
كروماتوكرامa مواد لييبدى نمونه (شـكلأ)، تقريبـاً برابـر

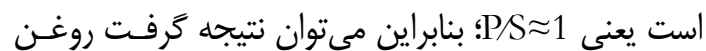

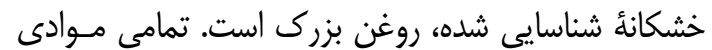
كه به عنوان جِسب، بست و حتى جلا و وارنسيش در آثـار
آناليز GC است [16,21,32]. سريشم حيوانى با حل شدن

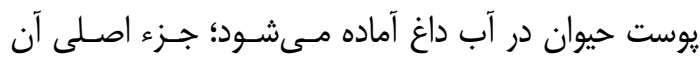

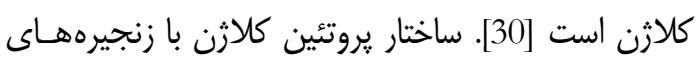

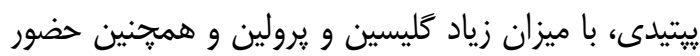

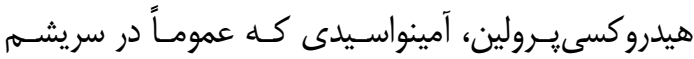

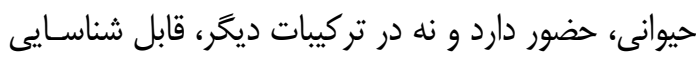

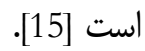

با توجه به قلههاى كليسين در كروماتوكرامها، ميزان فراوانى 2010.B.1-pink (كروماتوگرام bادر شكله) كمتر

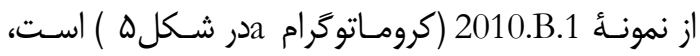

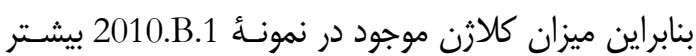

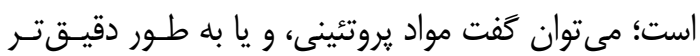

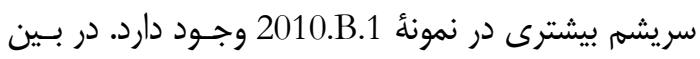

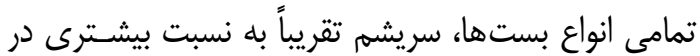

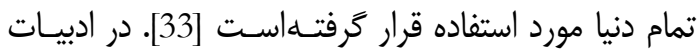

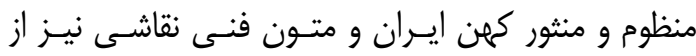

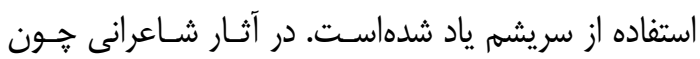

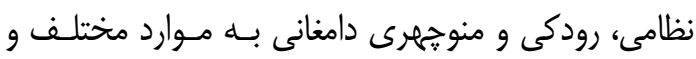

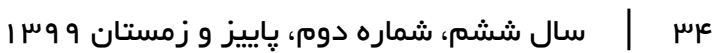




\section{7-r. بحث در نتايج مربـوط بـه مـواد معـدنى:}

تصاوير SEM تهيه شده از مقاطع نمونههاى لايهجينسى و

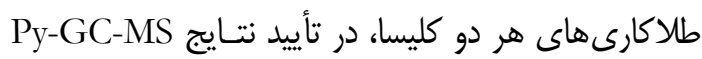

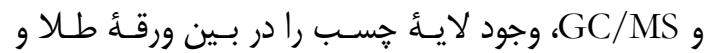

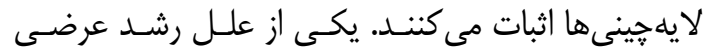

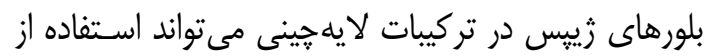
بست (ماده آلى) باشد. علت كم بودن فضاى خالى مـابين

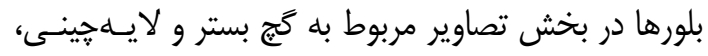

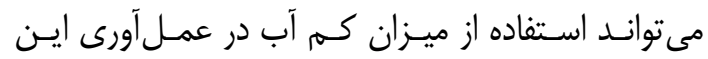
تركيبات باشد [40,41] همان طور كه در تصاوير SEM، بيشتر بلورهاى قابل باسل

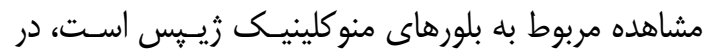

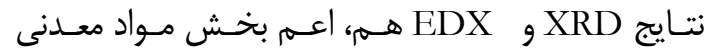

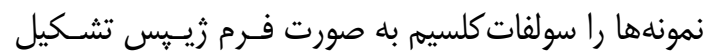

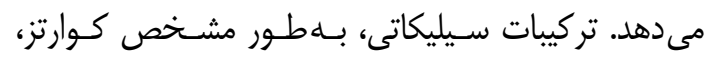
دومين فاز غالب شناسايى شدهاسـت. كلسـيم سـولفات در

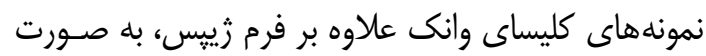

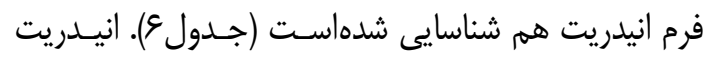

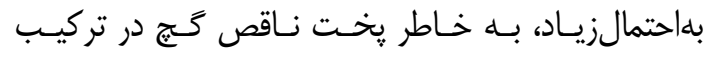

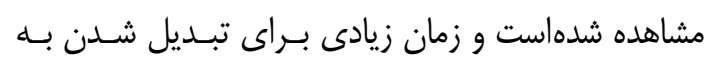

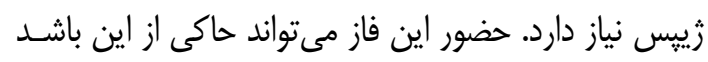

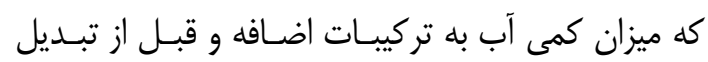

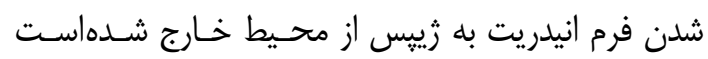
.[10,40,41]

وجود سيلسيوم در ساختار لايهجينى ها ناشى از حضور

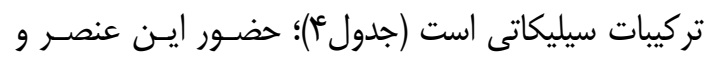

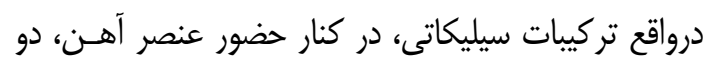
احتمال را در ييش رو قرار مىدهــدي يـا نمونسه در سـاختار خود اكسيدآهن و كوارتز به صورت جداءانه دارد، و يا ايسن كه رسى با عناصر منيزيـوم، آلومينيـوم، سيلسـيوم و آهـن

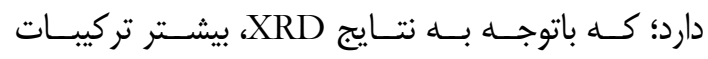

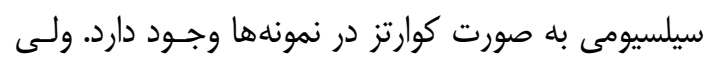
باتوجه به حضـور آلومينيـوم در كنـار سيلسـيوم در نتـايج حاصل از EDX، مىتوان كَفت ممكن است بخشى نيز به به

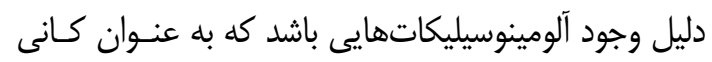
هاى رسى در كِل سرخ نمونهها وجود دارد.

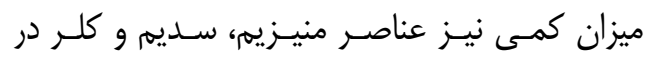

هنرى تاريخى كاربرد داشتهاند، تحت عنوان مواد لايهسـاز

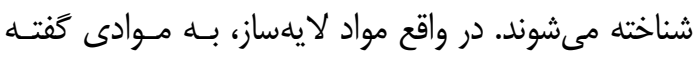
مىشوند كه با قرارگيرى بر روى يكى سطح ولى جامد كه يايسه

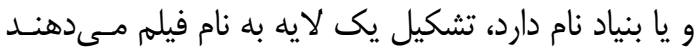

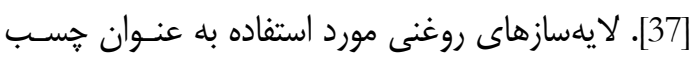

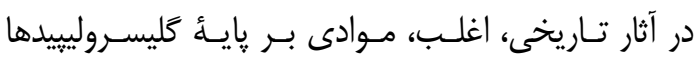

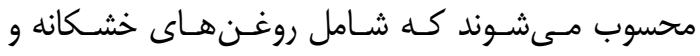

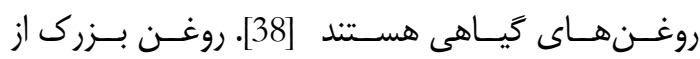

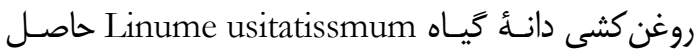
مىشود [34]. روغنهايى كه قابليت خشك شدن دارند، از دوران باستان و كلاسيك شناخته شده هستند [33].

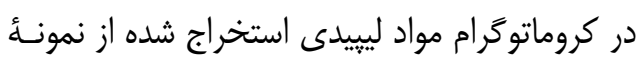

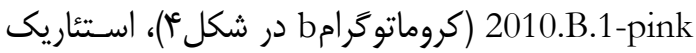
و يالميتيك اسيد، با فراوانى كمترى نسـبت بــه فراوانى

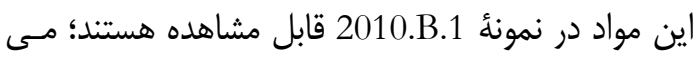
2010.B.1-pink توان نتيجه گرفـت، در سـاختار نمونسه مونه

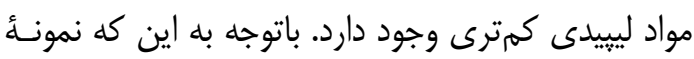

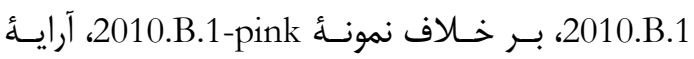
طلاكارى نيز دارد، مىتوان نتيجه گرفت از روغن بزرى

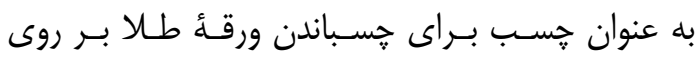

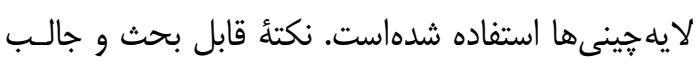

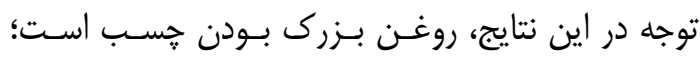

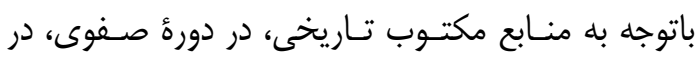

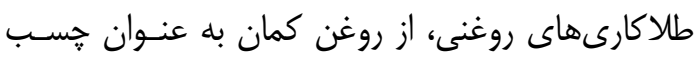

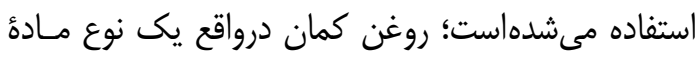

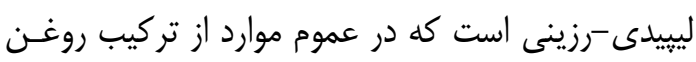

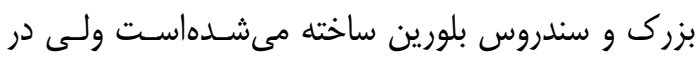
برخى منابع در روش تهيئ روغن كمان، از تركيب كهربـا

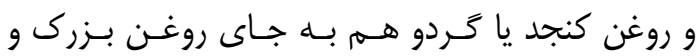

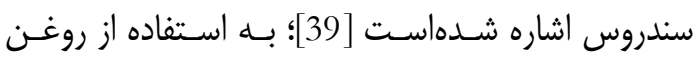
بزرك به عنوان جسب، بيشتر در آثار و منابع لاتين اشاره شدهاست.

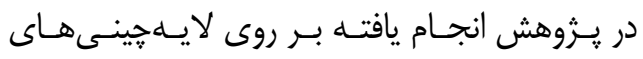
بناهاى عالى قايو، هشتبهشت و جهرلستون، سريشم بودن

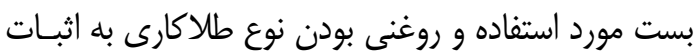
رسيدهاست. نوع روغن استفاده شده در ايـن طلاكـارىهـا نامعلوم است [10].

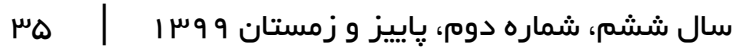




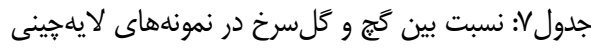

Tab; 9: Ratio between Gypsum and Red Bole

\begin{tabular}{|c|c|}
\hline Building Name & G:RB \\
\hline Vank & $5: 1$ \\
\hline Bethelehem & $3: 1$ \\
\hline Ali-Qapoo & $4: 1$ \\
\hline Hasht Behesht & $3: 2$ \\
\hline Chehel-Sotun & $4: 1$ \\
\hline
\end{tabular}

تركيب گج (زييس)، با يك نوع خاك رس حاوى كوارتز

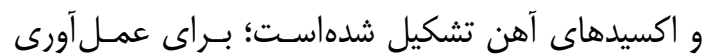

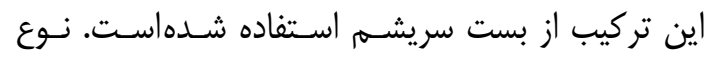
طلاكارى اجرا شده بـر روى لايسه هينـىهـا، طلاكـارى

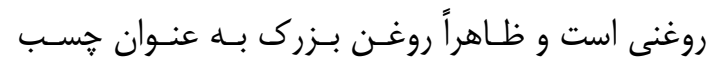

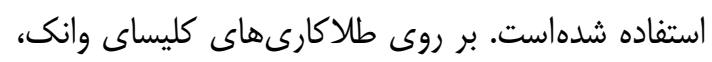

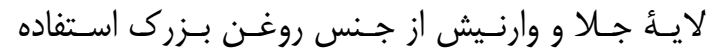

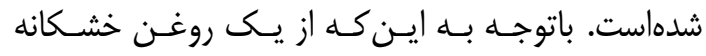
بلهعنوان حسب استفاده شدهاست، بـرخلاف مرسـومات هنرمندان دورة صفوى، شيؤ اجراى طاكارىهاى ايـن

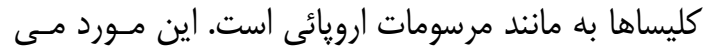

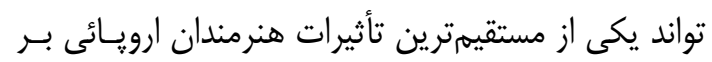

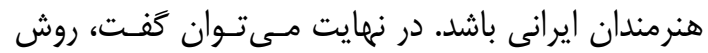
اجراى لايهجينى در كليساهاى ارمنى و بناهاى اسـلامى

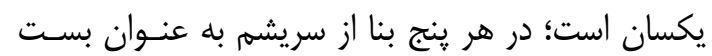

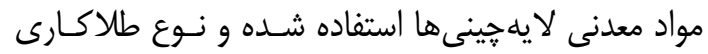

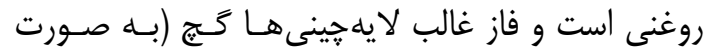

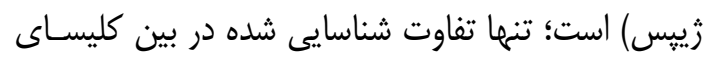

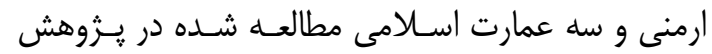
ييشين، باتوجه به نتايج XRD، تفاوت فازهاى موجود در

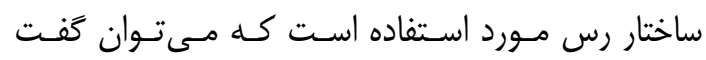
بهاحتمال زياد رس مورد استفاده متفاوت بودهاست.

\section{References}

[1] Hamsík M. The relief decoration of Medieval painting--pastiglia: origin and technique. Umeni. 1992;40(2):100-7.

[2] Yorke J. Dictionary of Art. Ed. Jane Turner. London: Macmilan Publishers Limited; Vol. 24; 1998.

[3] Wetherall. History and Techniques of Composition. In Book Gilding and
نمونهها شناسايى شدهاند. اغلب به همراه گج، ميزانى كلـر و منيزيم به عنوان ناخالصى همواره حضور دارند؛ ميزانى از

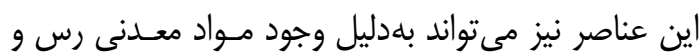
آلومينوسيليكاتهاى رسى باشد.

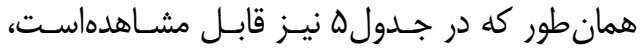

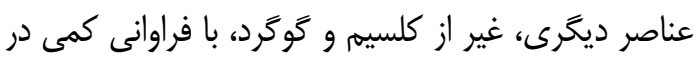
نمونههاى گَج بستر نيز شناسايى شدهاند. قسـمتى از ايـن

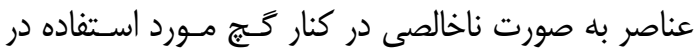

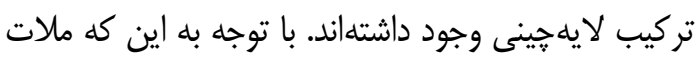

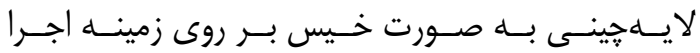

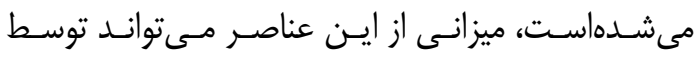

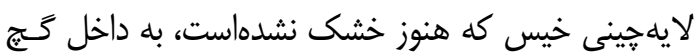

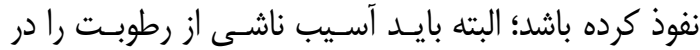

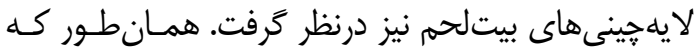

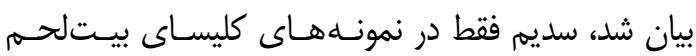
مشاهده شدهاست و بيشـتر آسـيب ناشـى از رطوبـت نيـز

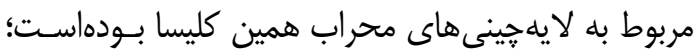

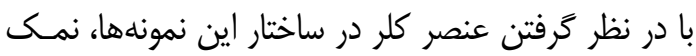
حاصل مىتواند به خاطر آسيبهاى رطوبت نيز باشد.

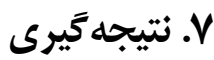

لايهجينى هاى كليساهاى وانك و بيتلحم بــهـ ترتيـب از
Surface Decoration. London: U.K. Institute for Conservation; 1991: 26-29.

[4] Bomford D, Dunkerton J, Roy A. Italian Painting before 1400. London: National Gallery Press; 1990.

[5] Frinta MS. Raised Gilded Adornment of the Cypriot Icons, and the Occurrence of the Technique in the West. Gesta. 1981 Jan 
1;20(2):333-47.

[6] Golombek L, Wilber D. The Timurid Architecture of Iran and Turan. Translated by Afsar K. and Kiani M.Y. Tehran: Publication of Cultural Heritage Organization; 1995. [in Persian] [خلمبك ليزا، ويلبر دونالد. معمـارى تيمـورى در ايـران و

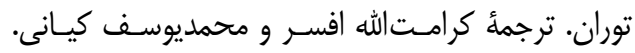

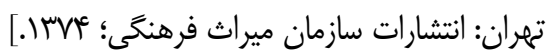

[7] Aqajani H. Painting Restorations (2). Asar Journal; 1980; 2, 3, 4: p. 160-175. [in Persian]

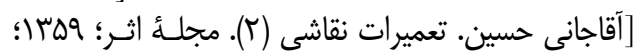

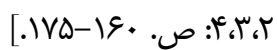

[8] Karimzadeye Tabrizi M.A. Biography and works of Old Iranian painters and some celebrities of Indian and Ottoman painters. Tehran: Mostofi Publications; 1997.

[كريمزاده تبريزى محمدعلى. احوال و آثار نقاشان ايـران

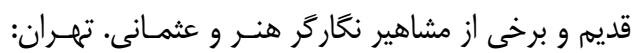

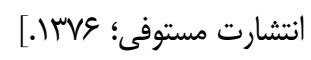

[9] Mayel-Heravi N. Book Designing in Islamic Culture. Mashhad: Astan Quds Razavi Research Foundation; 1993. [in Persian]

[مايلهروى نجيب. كتابآرايى در تمدن اسلامى. مشهر:

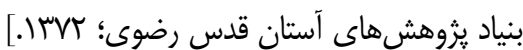

[10] Holakooei P, Abed-Esfehani A, Samanian S. Aslani H. A Technological Study on the Pastiglia of Gilded Substrates at Safavid Period in Isfahan (Based on the Pastiglias of Ali-Qapoo, Chehel-Sotun and HashtBehesht). Journal of Art University; 2008; 2: 37-56. [in Persian]

] هلاكويى يرويز، عابد اصفهانى عباس، سـامانيان صـمد،

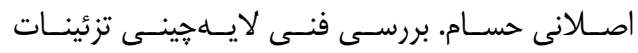

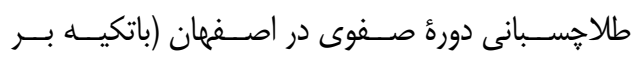

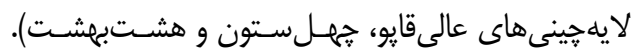

نامة هنرهاى تجسمى و كـاربردى، دوفصـلنامئ دانشـعاه

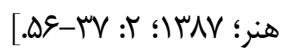

[11] Nadolni J. The Techniques and Use of Gilded Relief Decoration by Northern European Painters, c. 1200-1500. London: University of London; 2000. [Unpublished PhD thesis]

[12] Bonaduce I, Colombini MP, Diring S. Identification of garlic in old gildings by gas chromatography-mass spectrometry. Journal of Chromatography A. 2006 Feb
24;1107(1-2):226-32.

[13] Colombini MP, Modugno F, Giacomelli M, Francesconi S. Characterisation of proteinaceous binders and drying oils in wall painting samples by gas chromatography-mass spectrometry. Journal of Chromatography A. 1999 Jun 18;846(1-2):113-24.

[14] Colombini MP, Modugno F, Fuoco R, Tognazzi A. A GC-MS study on the deterioration of lipidic paint binders. Microchemical Journal. 2002 Oct 1;73(12):175-85.

[15] Colombini MP, Modugno F. Characterisation of proteinaceous binders in artistic paintings by chromatographic techniques. Journal of Separation Science. 2004 Feb;27(3):147-60.

[16] Colombini MP, Andreotti A, Bonaduce I, Modugno F, Ribechini E. Analytical strategies for characterizing organic paint media using gas chromatography/mass spectrometry. Accounts of chemical research. 2010 Jun 15;43(6):715-27.

[17] Lluveras A, Bonaduce I, Andreotti A, Colombini MP. GC/MS analytical procedure for the characterization of glycerolipids, natural waxes, terpenoid resins, proteinaceous and polysaccharide materials in the same paint microsample avoiding interferences from inorganic media. Analytical chemistry. 2010 Jan 1;82(1):376-86.

[18] Degano I, Modugno F, Bonaduce I, Ribechini E, Colombini MP. Recent advances in analytical pyrolysis to investigate organic materials in heritage science. Angewandte Chemie International Edition. 2018 Jun 18;57(25):7313-23.

[19] Tenorio AL, La Nasa J, Ferriani B, Colombini MP, Modugno F. The chemistry of pastels: Investigation of the organic materials in a drawing by Umberto Boccioni. Journal of Cultural Heritage. 2019 Jan 1;35:235-41.

[20] Arjonilla P, Dominguez-Vidal A, CorreaGomez E, Rubio-Domene R, LluverasTenorio A, Ayora-Cañada MJ, Colombini MP. Characterization of organic materials in the decoration of ornamental structures in the Alhambra monumental ensemble using gas-chromatography/mass spectrometry (GC/MS). Microchemical Journal. 2018 Jul 1;140:14-23. 
[21] Bonaduce I, Blaensdorf C, Dietemann P, Colombini MP. The binding media of the polychromy of Qin Shihuang's Terracotta Army. Journal of Cultural Heritage. 2008 Jan 1;9(1):103-8.

[22] Bonaduce I, Ribechini E, Modugno F, Colombini MP. Analytical approaches based on gas chromatography mass spectrometry (GC/MS) to study organic materials in artworks and archaeological objects. Topics in Current Chemistry. 2016 Feb 1;374(1):6.

[23] Devièse T, Ribechini E, Castex D, Stuart B, Regert M, Colombini MP. A multianalytical approach using FTIR, GC/MS and Py-GC/MS revealed early evidence of embalming practices in Roman catacombs. Microchemical Journal. 2017 Jul 1;133:4959.

[24] Huspian Sh. Architecture of Isfahan's Churches. Peyman Quarterly Periodical Journal; 2007; 40. [in Persian]

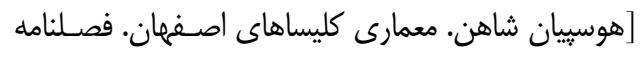

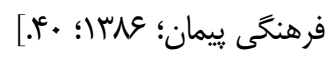

[25] Carswell J. New Julfa the Armenian Churches and other Buildings. Oxford: Clarendon Press; 1968.

[26] Haghnazarian A. Armenian Churches of Isfahan's New Julfa. Tehran: Farhangestan-e Honar; 2006. [in Persian] ]حق نظريان آرمن. كليساهاى ارامنهُ جلفاى نو اصـفهان.

$$
\text { تهران: فرهنگستان هنر؛ هرسا. }
$$

[27] Hamzavi Y. Finding and Old Inscription in Vank (Surp Amenaprgich) Cathedral in Isfahan. Bi-annual Journal of Restoration Science and Cultural Heritage; 2014; 4: p.49-58. [Original in Persian with English Abstract]

] حمزوى ياسر. كشف كتيبهاى كهن در كليسـاى وانـى

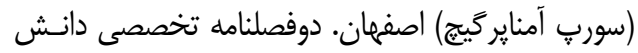

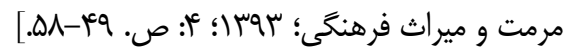

[28] Ashiian M.V. Album All Saviours Cathedral New Julfa, Iran. A Publication of the Diocesan Council of Armenians in Iran and India; 1975.

[29] Qukasian H. Vank Cathedral of Isfahan's Julfa. Armaghan Journal; 1972; 11, 12: p.800-4. [in Persian]

$$
\begin{aligned}
& \text { [قوكاسيان هراند. كليساى وانكى جلفاى اصـفهان. مجلــ }
\end{aligned}
$$

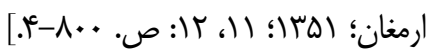

[30] Vandenabeele P, Wehling B, Moens L, Edwards H, De Reu M, Van Hooydonk G. Analysis with micro-Raman spectroscopy of natural organic binding media and varnishes used in art. Analytica Chimica Acta. 2000 Feb 29;407(1-2):26174.

[31] Cornelis K. Manual of mineralogy.Translated by Farid M, Modaberi S. Tehran: iup; 2007.

[كلاين كرنليس. راهنماى كانىشناسى. ترجمه. مر فريد،

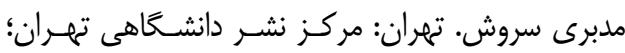

[.

[32] Colombini M.P, Gautier G. GC/MS in the characterization of Protein Paint Binders. In: Colombini M.P, Modugno F, Editors. Organic Mass Spectroscopy in Art and Archaeology. United Kingdom: Wiley, 2009: p. 237-59.

[33] Taft W, Mayer J.W. The Science of Paintings. New York: Springer; 2000.

[34] Karimy A.H. Traditional varnishes in the history of Persian Painting. Specialized course on the conservation of historical, cultural and artistic monuments using organic and inorganic coatings; 2013: p. 112.

[كريمى اميرحسـين. يوشـش دهنــهـهـاى سـنتى مـورد

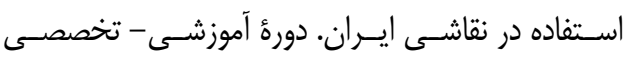

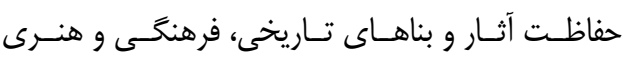

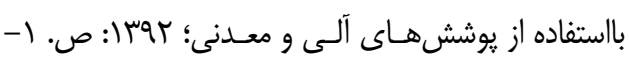

$[.14$

[35] Bonaduce I, Andreotti A. Py-GC/MS of Organic Paint Binders. In: Colombini M.P, Modugno F, Editors. Organic Mass Spectroscopy in Art and Archaeology. United Kingdom: Wiley, 2009: p. 303-26.

[36] Colombini M.p, Modugno F, Ribechini E. GC/MS in the Characterization of Lipids. In: Colombini M.P, Modugno F, Editors. Organic Mass Spectroscopy in Art and Archaeology. United Kingdom: Wiley, 2009: p. 191-213.

[37] Kleiner L.M. Binding Media, Varnishes \& Adhesives Artist's materials. Translated by Farahmand-e borujeni H. Isfahan: Goldasteh Publications; 2009.

$$
\begin{aligned}
& \text { [كلاينر ليليان ماسشلين. خواص مــواد بـراى هنرمنـدان: }
\end{aligned}
$$

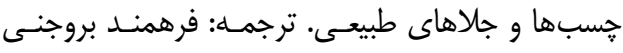

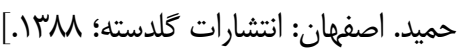

[38] Colombini M.P, Modugno F. Organic 
Materials in Art and Archaeology. In: Colombini M.P, Modugno F, Editors. Organic Mass Spectroscopy in Art and Archaeology. United Kingdom: Wiley, 2009: p. 3-36.

[39] Nemati-babaylou A, Azadi M, Najafi F, Mohammadi-Achachlouie. Kaman Oil; Imitation, Innovation of Localisation? The first international Conference on Arts and Crafts in Iranian-Islamic Culture and Civilization: Declining arts in focus; 2016: 1-11. [in Persian]

[نعمتى بابايلو على، آزادى مهرناز، نجفى فرهود، محمدى

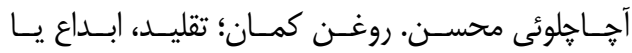
بومى سازى؟. نخستين همايش بين المللى هنر و صناعات

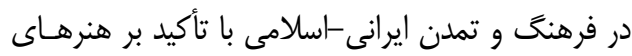
رو به فراموشى؛ هوسا: ص. (-1).

[40] Mishmastnehi M. The Application of Crystallographic Interpretation on Technical Study of Gypsum-Based Historical Materials (Case studies of stucco decoration of Kuh-e Khwaja and Gypsum
Mortars from Shadiakh and Alamut). JRArch, 2015; 2: 1-14. [Original in Persian with English Abstract]

[ميشمستنهى مسله. كاربرد تحليل هاى بلورشناسى در

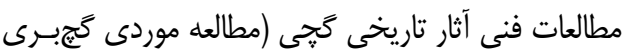

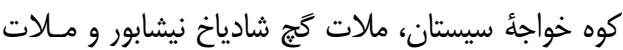

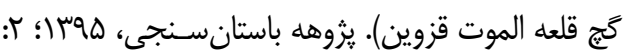

ص.

[41] Hamzavi Y, Sardari A.M. Investigation of Natural ad Industrial Stabilizer for Usage in Stucco Decoration in Seti Fatima Mosoleum. The First Symposium of Material Science and Conservation of Cultural- Historical Heritage; 2012: p. 115. [Original in Persian with English Abstract]

]حمزوى ياسر، سردارى على محمد. استفاده از آناليزهاى

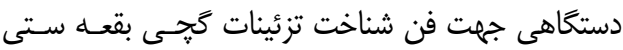

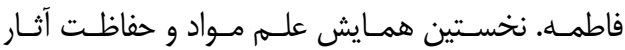

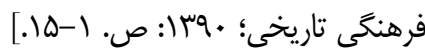

